\title{
LA GUERRA FRÍA Y LOS EMPRESARIOS ESPAÑOLES: LAARTICULACIÓN DE LOS INTERESES ECONÓMICOS DE ESTADOS UNIDOS EN ESPAÑA, 1950-1975*
}

\author{
NÚRIA PUIG RAPOSO \\ Universidad Complutense de Madrid \\ ADORACIÓN ÁLVARO MOYA ${ }^{b}$ \\ Universitat de Barcelona
}

\begin{abstract}
RESUMEN
En este trabajo se examinan algunos efectos de la alianza política y militar entre España y Estados Unidos durante los años cincuenta y sesenta del siglo XX. Se examina la ayuda técnica, entendida como el conjunto de programas oficiales, contratos e inversiones privadas que sirvieron para transferir a España las técnicas de producción y organización norteamericanas. El análisis cuantitativo y cua-
\end{abstract}

\footnotetext{
* Agradecemos la ayuda prestada por los responsables de los siguientes archivos: Archivo General de la Administración, Archivo del Ministerio de Asuntos Exteriores, Archivo Suanzes, Ford Foundation Archives, Asociación para el Progreso de la Dirección, Hagley Museum \& Library y National Archives and Records Administration, así como de la Biblioteca de la Universidad de Glasgow. Las sugerencias de dos evaluadores anónimos merecen también nuestra gratitud. La investigación forma parte del proyecto del Plan Nacional de I+D+I SEC2000-1084.

a Departamento de Historia e Instituciones Económicas II, Facultad de C.C. Económicas y Empresariales, Campus de Somosaguas, 28223 Pozuelo, Madrid. nuriapuig@ccee.ucm.es.

${ }^{b}$ Departament de Història i Institucions Econòmiques, Facultat d'Econòmiques, Avda. Diagonal, 690, 4 Planta, 08034 Barcelona. alvaromoya@ccee.ucm.es.
} 
litativo revela que tanto dicha ayuda como los círculos pro-americanos formados a su alrededor, en parte sustentados en relaciones de negocios anteriores, fueron esenciales en la articulación de los intereses económicos estadounidenses en España. El caso español muestra que la política económica exterior norteamericana de la Guerra Fría favoreció, si bien sólo indirectamente, a la comunidad empresarial de aquel país. En segundo lugar, el trabajo proporciona material e ideas para analizar el «milagro» español como un proceso de crecimiento exógeno.

Palabras clave: Estados Unidos, empresariado español, ayuda técnica, círculos pro-americanos, crecimiento exógeno

\begin{abstract}
This article examines some effects of the political and military alliance between Spain and the United States on the Spanish business community in the 1950s and 1960s. The technical aid is taken to be the set of official programs and private contracts and investments that helped disseminate in Spain the techniques and ideas associated with the American model. The articulation process of the economic interests of the United States in Spain is quantitatively and qualitatively analysed. Our research reveals that technical aid and the pro-American circles formed around it, which were partially based on existing business relations, were essential to such process. The Spanish case shows therefore, first, that US foreign economic policy favoured, even if only indirectly, American business during the Cold War. Second, this work provides material and ideas to analyse the Spanish «miracle» as a rather exogenous growth process.
\end{abstract}

Keywords: United States, Spanish business community, technical aid, proAmerican circles, exogenous growth process

JEL Classification: F23, F35, N84, O12, O19

\title{
1. INTRODUCCIÓN
}

Además de modificar radicalmente la geografía política y militar del mundo durante la segunda mitad del siglo XX, la Guerra Fría aceleró los procesos de integración internacional y de convergencia económica y social entre los Estados Unidos y sus aliados europeos y entre la Unión Soviética y los suyos. Estos procesos, que subyacen al extraordinario crecimiento de la renta registrado en las décadas de los cincuenta y sesenta en los dos bloques, se vieron a su vez favorecidos por la transmisión de conocimientos económicos y empresariales de las 
potencias a sus socios del Viejo Mundo. En el Atlántico, los programas internacionales de ayuda e intercambio económico, técnico y científico, la actividad de las empresas multinacionales y el comercio exterior fueron los vehículos de difusión del modelo capitalista de organización económica y social más visibles en los veinte años siguientes a la derrota de Hitler. Concluida la Guerra Fría hace una década, nuestro conocimiento del contenido y de los efectos de esa masiva transmisión de ideas y técnicas organizativas en el terreno empresarial es aún débil ${ }^{1}$. Y es que la dimensión diplomática y macroeconómica de la Guerra Fría ha sido objeto de mucha más atención que otros aspectos del conflicto².

A este lado del telón de acero, los análisis del Plan Marshall han hecho sombra a los de cualquier otro proceso asociado a la influencia económica y social de la Guerra Fría en Europa ${ }^{3}$. El cincuentenario de este programa de ayuda económica, más el renovado liderazgo de los Estados Unidos, han dado aliento en los últimos diez años a numerosos proyectos internacionales de investigación sobre la difusión del modelo americano de organización económica y empresarial. Buena parte de las publicaciones resultantes se ha ocupado del papel de las comisiones de productividad y de las instituciones dedicadas a la dirección y organización de empresas. Pero la palabra clave, capaz de movilizar una cantidad de recursos humanos y materiales enorme, ha sido americanización $n^{4}$, un término tan cómodo como polémico que ha logrado centrar la atención de muy diversos historiadores sobre la influencia de los Estados Unidos en las instituciones económicas y sociales de sus aliados.

${ }^{1}$ Es habitual situar el final de la Guerra Fría en 1989, cuando se derribó el muro de Berlín, pero el desmantelamiento de la compleja red de organismos que controlaban el comercio entre los dos bloques no se produjo hasta 1994

${ }^{2}$ Para la visión diplomática, véase Garthoff (1985). Recientemente ha cobrado fuerza el análisis del papel desempeñado por los satélites o small allies, entre los que se encontraría España, para modificar la política exterior de las potencias americana y soviética en favor de sus propios intereses, aprovechando la coyuntura de la Guerra Fría. La progresiva y reciente desclasificación de los documentos depositados en archivos del antiguo eje comunista ha dado pie a varios estudios en este sentido. El proyecto más ambicioso, y más internacional, lo constituye el Cold War International History Project (CWIHP), financiado por The Woodrow Wilson International Center for Scholars.

${ }^{3}$ Para un estudio reciente e influyente, véase Hogan (1987). Una mayor atención al tejido empresarial estadounidense, en Sanford (1987).

${ }^{4}$ Entre los trabajos dedicados al productivismo figuran los de Maier (1987), Zeitlin y Harrigel (2000) y Barjot (2002). La difusión del modelo de gestión de empresas americano es el tema de Guillén (1994), Amdam (1996), Kipping y Bjarvar (1998), Kipping y Tiratsoo (2002) y, parcialmente, de Barjot y Réveillard (2002), donde está incluido un trabajo sobre España de Lorenzo Delgado. La influencia en y a través de la educación empresarial es el tema de Engwall y Zamagni (1998) y de Gourvish y Tiratsoo (1998). Especialmente influyente, y controvertido, ha sido el libro de Djelic (1998). En Barjot, Lescent-Giles y Ferrière (2002), por último, se recogen varios trabajos dedicados al impacto macroeconómico de la americanización. 
España fue uno de los aliados tardíos, además de poco desarrollados, del país americano. El enfrentamiento entre los Estados Unidos y la Unión Soviética en el antiguo escenario de la ocupación japonesa llevó a los norteamericanos a buscar nuevos aliados militares en la periferia europea a partir de 1950. Hasta finales de la década, cuando comenzó la lenta normalización económica española, Estados Unidos oficiaría de hecho como embajador de España en los foros de la Europa democrática ${ }^{5}$. La relación entre la España de Franco y la primera potencia occidental fue bautizada en 1950 por un crédito a través del Export-Import Bank (Eximbank) de 62,5 millones de dólares y formalizada tres años después por un convenio de cooperación militar y económica ${ }^{6}$. Aunque la ayuda económica brindada resultó inferior a la de los países Marshall, los mecanismos fueron similares ${ }^{7}$. Hubo así en España también ayuda técnica, una partida de la ayuda económica modesta cuantitativamente, pero de gran interés cualitativo, que en los países del Plan Marshall gestionaron las comisiones nacionales de productividad -el germen de la posterior Organización Económica Europea de Cooperación, OEEC- con fondos tanto públicos como privados y con el objetivo último de transferir ideas y técnicas económicas y empresariales al Viejo Continente. ¿Qué papel desempeñó esta clase de ayuda, más sutil, en la defensa de los intereses económicos de Estados Unidos en España? ¿En qué medida influyeron esos intereses en el empresariado español? Para responder a estas preguntas, hemos centrado nuestra investigación en la relación, necesariamente compleja, que se estableció después de la Segunda Guerra Mundial entre los programas oficiales de ayuda, los contratos e

${ }^{5}$ Véanse los trabajos de Marquina (1986), Portero (1989), Edwards (1994), Guirao (1998), Liedtke (1998) y Jarque (1998), por citar sólo los más recientes, tributarios todos ellos de la investigación seminal de Viñas (1981a). Viñas (2003) constituye una reedición, revisada y ampliada, del libro de 1981. El interés de los historiadores políticos y de las relaciones internacionales se ha centrado en la situación más o menos anómala de España en la política del Departamento de Estado norteamericano, y en el apoyo político de Estados Unidos a la dictadura. Que el acuerdo era esencialmente militar es algo que nadie discute.

${ }^{6}$ El Eximbank se constituyó en 1934 como entidad financiera dependiente del Gobierno estadounidense con el doble objetivo de promocionar las exportaciones de este país y de ser instrumento de su política exterior. Así, la concesión de créditos exteriores por parte de este organismo, generalmente a proyectos privados concretos, se simultaneó con los programas de asistencia militar, económica y técnica a Europa. Sobre esta institución, véase Becker y McClenahan (2003). Por otro lado, el cincuentenario de los Pactos de Madrid está sirviendo de catalizador de varios proyectos interdisciplinares de investigación, en los que participan las autoras de este artículo. Un primer resultado se encuentra en Niño (2003).

${ }^{7}$ Frente a los aproximadamente 1.500 millones de dólares que percibió España entre 1953 y 1963, el Reino Unido había recibido 8.353, 5.343 Francia, 2.972 la República Federal de Alemania y 2.679 Italia. Véase Calvo (2002, p.256). Los países pequeños, como Holanda, Grecia, Austria o Bélgica, resultaron grandes beneficiarios en términos relativos del Plan Marshall. Las ayudas posteriores se concentraron en los países de la periferia europea, especialmente Grecia y Turquía. Los mayores beneficiarios de los créditos del Eximbank fueron, no obstante, España y Yugoslavia. Vid. Puig y Álvaro (2003, p. 14). 
inversiones del sector privado, el modelo americano, y la defensa de los intereses, viejos o nuevos, de la economía estadounidense en nuestro país. Con este fin hemos reconstruido cuantitativa y cualitativamente el proceso de articulación de estos últimos entre 1950 y 1975, examinando tanto el entramado institucional y personal de la ayuda técnica oficial y el proceso de transferencia de conocimientos desencadenado por la misma, como las inversiones directas de origen americano en el país y, finalmente, los círculos empresariales pro-americanos creados o reforzados durante este periodo. El concepto de círculos pro-americanos se desarrolla en el artículo para explicar cómo se articularon los intereses públicos y privados de los dos países, y para poner de manifiesto que los empresarios españoles tecnológicamente más avanzados, con o sin lazos previos con empresas norteamericanas, supieron utilizar las oportunidades brindadas por la llamada ayuda técnica y por las nuevas relaciones hispano-norteamericanas. Estas oportunidades eran inseparables de los privilegios que disfrutaron las compañías americanas como fuentes de tecnología hasta los setenta, de la dependencia tecnológica estructural de la empresa española, y de la protección del mercado español, moneda de cambio en las negociaciones entre los empresarios españoles y americanos. El resultado final del proceso fue una relación económica muy desigual entre los dos países y una dependencia muy notable de los empresarios españoles respecto de los Estados Unidos ${ }^{8}$. Investigaciones futuras deberán, no obstante, perfilar mejor el retrato analítico de los empresarios pro-americanos que trazamos en las páginas siguientes ${ }^{9}$.

\section{LA EXPORTACIÓN DEL MODELO AMERICANO A EUROPA}

El final de la Segunda Guerra Mundial dio paso a una influencia sin precedentes de los Estados Unidos en Europa Occidental, así como a una internacionalización, también sin precedentes, de la economía norteamericana. Los actores más visibles de este último proceso fueron las empresas multinacionales de capital estadounidense, que experimentaron un crecimiento espectacular hasta los años setenta, cuando la crisis internacional y la creciente competitividad de sus rivales europeas y japonesas empezaron a frenarlo. Su actividad fue paralela a la de las agencias ofi-

${ }^{8}$ Mientras España no pasó de significar un 1 por ciento de la inversión o el comercio exterior norteamericano, más de la mitad de la inversión extranjera en España procedía de este último, que también se consolidó como su primer socio comercial.

${ }^{9}$ En particular cuando sepamos más sobre la construcción de las bases y sobre la industria militar. En Oromí (1957, vol. II) se dan algunas pistas. El principal contratista fue, al parecer, el consorcio Brown-Raymond-Walsh, si bien las decisiones se tomaban en la delegación militar de Estados Unidos en España, de la que era director Harold N. Hockensmith. El coste total del programa ascendió a 35 millones de dólares. 
ciales administradoras del Plan Marshall y a la ambiciosa política de desarrollo económico mundial auspiciada por los Estados Unidos desde principios de los años cincuenta. La rotundidad con que, en las décadas siguientes, se impuso el liderazgo político y militar de ese país en la Europa liberada, unida a la rápida adaptación del modelo económico y social estadounidense a los diversos contextos nacionales europeos y a la relación fluida que aparentemente existió entre los gestores públicos de la política económica exterior americana y la comunidad empresarial, alimentarían hasta prácticamente el final de la Guerra Fría la idea de que la internacionalización de la economía estadounidense se apoyó en un consenso muy amplio. En virtud de este proceso, una parte considerable de los gobernantes, expertos, burócratas y empresarios relacionados con la proyección internacional de la economía americana defendieron el aumento de los presupuestos y de la capacidad de intervención de las agencias, fundaciones y empresas norteamericanas en todo el mundo. Enarbolando con distinto grado de intensidad las banderas de la democracia liberal y de la libre empresa, las instituciones económicas, públicas y privadas, de la Guerra Fría habrían desempeñado un papel tan crucial como controvertido en la llamada americanización del mundo.

Durante mucho tiempo, los historiadores norteamericanos se han dedicado a analizar el origen y los efectos de esa coincidencia de intereses sobre la economía americana. En la nueva izquierda en particular ha anidado la idea de que el fenómeno, fruto parcial de la expansión europea de las multinacionales en los años veinte y del espíritu de concertación del New Deal en los treinta, sostuvo la política exterior de los Estados Unidos durante la Guerra Fría, así como los muchos negocios e inversiones asociados a la misma. De la voluntad de contribuir a que la recuperación de Europa Occidental, de la que dependía una parte importante de la economía americana, fuera lo más rápida posible, se pasaría sin demasiados traumas a promover la transferencia masiva del modelo de producción y consumo norteamericano a sus aliados y la creciente militarización de la industria transatlántica, mientras el desarrollismo liberal característico de la posguerra se desvirtuaba, imponiendo, entre otras cosas, controles estratégicos al comercio ${ }^{10}$. Fuera del ámbito atlántico, y según esta interpretación, la armoniosa intervención de funcionarios y empresarios de la primera potencia capitalista también tuvo un papel notable en la difusión de técnicas y de ideas orientadas a combatir la influencia comunista a través del incremento de la productividad y del desarrollo económico. Los programas de ayuda técnica, muy en particular, constituirían el vehículo esencial de esa misión nacional de educación económica y de generación de negocios internacionales.

${ }^{10}$ Controles para los que Estados Unidos defendía una postura muy estricta, y que finalmente tuvo que relajar ante las disensiones que fueron surgiendo con los europeos y que amenazaban la cohesión dentro de la OTAN. Además, según estudios recientes, estos controles, más que evitar el desarrollo armamentístico e industrial soviético, sirvieron para afianzar los intereses nacionales en el comercio entre ambos bloques y fomentar el proceso de integración europea, amortiguando sus efectos sobre los productores europeos occidentales. Véase Segreto (2001) y McGlade (2001). 
El final de la Guerra Fría ha estado acompañado por una importante revisión de la historia de las relaciones entre la política económica exterior norteamericana y los empresarios de vocación internacional. Jacqueline McGlade (2000) ha desvelado muchos desencuentros entre los empresarios implicados en el diseño y la gestión de la asistencia técnica y económica a Europa durante la primera fase de la Guerra Fría. Según esta autora, el estallido del conflicto dio al traste con la convergencia de intereses entre políticos y empresarios, abandonándose los planes de reconstrucción y desarrollo global de Europa a favor de la seguridad estratégica en el seno de la Organización del Tratado del Atlántico Norte (OTAN). La economía, en resumen, se puso al servicio de la política y la ideología. También los departamentos internacionales de las principales asociaciones empresariales revelan que hubo discrepancias acerca del tipo de liderazgo que los Estados Unidos debían promover y de los instrumentos que debían ponerse a su servicio ${ }^{11}$.

El proceso de americanización de Europa Occidental estuvo muy relacionado con el crecimiento económico estadounidense, pero sobre todo con las dos guerras mundiales, que aumentaron la dependencia de Europa de la nueva potencia y facilitaron la penetración comercial y organizativa norteamericana en el Viejo Continente $^{12}$. No fue éste un proceso lineal, ciertamente, pero aceleró la convergencia tecnológica y creó modelos híbridos de producción, consumo y relaciones industriales en Europa y Japón ${ }^{13}$. El capital americano también influyó en el ritmo y la intensidad de la convergencia. Entre 1929 y 1970, Europa Occidental pasó de absorber casi un 18 por ciento de la inversión directa norteamericana en el exterior a más del 31, y entre 1945 y 1965 el 85 por ciento de la inversión extranjera en Europa Occidental fue estadounidense ${ }^{14}$. El Tratado de Roma y la posterior creación del Mercado Común Europeo marcaron el inicio de una nueva época, marcada por los intentos estadounidenses de activar la exportación y la inversión a través de una mayor adaptación a las instituciones europeas, y frenar la llegada de produc-

${ }^{11}$ McGlade confirma así estudios anteriores de Wilkins (1974), en los que se cuestiona que el Departamento de Estado favoreciera los patrones de crecimiento de las multinacionales norteamericanas. La patronal americana más influyente en la política exterior americana fue la National Association of Manufacturers (NAM), que englobaba a las principales compañías americanas. Adalid de la libre empresa y enemiga de la cultura económica socialista (sic) de la Europa de posguerra, la NAM desarrolló, a través de un departamento específico de relaciones internacionales, una intensa labor de análisis y de presión pública. La documentación más importante se encuentra en HML, NAM Papers, Serie I, cajas 76, 77 y 78. En ella se pone de manifiesto asimismo que el déficit de la balanza de pagos americana está en el origen de muchas de esas desavenencias.

12 Wilkins (1974)

${ }^{13}$ La tradición industrial de cada país, la dimensión y naturaleza de sus empresas y mercados, y el interés de sus líderes políticos y económicos determinaron el rumbo de la transferencia. Véase nota 4.

${ }^{14}$ US Department of Commerce (1975, vol. 2, pp. 870-871). 
tos y capitales procedentes de este continente ${ }^{15}$. En ese contexto, el acceso a mercados más jóvenes de la periferia europea, como España, cobraría un interés extraordinario, especialmente para las empresas de los sectores donde las multinacionales europeas eran más competitivas.

\section{LOS EMPRESARIOS NORTEAMERICANOS Y ESPAÑA}

De las relaciones económicas y empresariales entre los Estados Unidos y España sabemos poco. El capital norteamericano, como el alemán, dio aliento financiero y tecnológico a las industrias de base científica y a la construcción de las primeras infraestructuras urbanas en el curso de la segunda revolución industrial, pero se mantuvo muy por detrás del de Gran Bretaña y Francia hasta bien entrado el siglo XX. Ahora bien, desde entonces, la posición de Estados Unidos mejoró velozmente: de ser el cuarto país inversor en 1918, con 17,8 millones de pesetas y muy por detrás del Reino Unido y Francia, pasó a ser dos décadas más tarde el segundo, con 1.797,57 millones de pesetas ${ }^{16}$.

En el Cuadro 1 puede observarse que el final de la Segunda Guerra Mundial supuso un punto de inflexión en la inversión directa norteamericana. El nivel de 1929 no se alcanzó hasta 1961, tras un máximo en 1943. El capital norteamericano se centró inicialmente en los servicios públicos -que incluían las telecomunicaciones- $\mathrm{y}$, en menor medida, en el petróleo, la automoción, la generación y el equipamiento eléctricos y la distribución cinematográfica ${ }^{17}$. Posteriormente, y sin entrar a cuestio-

\footnotetext{
${ }^{15}$ HML, NAM Papers, serie IV, caja 22. El programa que la patronal quería imponer a la Administración era el «multinational task force» (1969). La NAM arremetió contra los informes críticos de Naciones Unidas y la OCDE sobre las multinacionales americanas, especialmente en el Tercer Mundo.

${ }^{16}$ Datos de Tascón (2002, pp. 2 y 5).

${ }^{17}$ Las multinacionales pioneras fueron, por orden de antigüedad, Singer, Kodak, Gulf Oil, Socony-Vacuum Oil, Ford, General Motors, International Telephone \& Telegraph (ITT), 20 ${ }^{\text {th }}$ Century Fox Film, Consolidated Electric \& Gas, General Electric, Metro-Goldwyn-Mayer, Western Electric, Westinghouse Electric, Coca Cola, Worthington Pump \& Machinery, Warner Bros Pictures, Columbia Pictures, Atlantic Refining Company, Texaco, Firestone y National Cash Register, seleccionando las más conocidas. Nuestra reconstrucción se basa en una relación elaborada en 1950 por la embajada americana en Madrid, habiéndose comprobado la fecha de creación de las empresas operativas en ese año. Esta relación, por tanto, proporciona un número mínimo de las empresas norteamericanas en España en la primera mitad del siglo XX. NARA, Record Group 469, entrada 387, caja 31. Los datos sobre filiales establecidas anteriormente a la guerra civil que aparecen en esta relación concuerdan con las cifras aportadas por otros autores en cuanto a su número para esas fechas, particularmente Tascón (2002, p. 34). Sin embargo, este mismo autor ofrece, de acuerdo con una fuente alternativa, cifras muy inferiores en un trabajo posterior: vid. Tascón (2003, p. 287). La información que proporciona Wilkins es muy fragmentaria, pero muestra que la inversión en España se adaptaba al patrón europeo en cuanto a inversión en servicios públicos, no así en bienes de consumo, donde las filiales como las de Singer o Kodak- solían ser estrictamente comerciales. Véase Wilkins (1974).
} 


\section{CUADRO 1}

INVERSIÓN DIRECTA DE ESTADOS UNIDOS EN ESPAÑA Y LA C.E.E. (millones de dólares corrientes de EE.UU.)

\begin{tabular}{|c|c|c|c|c|c|c|c|c|c|}
\hline & \multirow{2}{*}{$\begin{array}{c}\text { Inversión } \\
\text { acumulada }\end{array}$} & \multirow{2}{*}{$\begin{array}{c}\text { Variación } \\
\text { anual } \\
\text { de la } \\
\text { inversión } \\
\text { acumulada }\end{array}$} & \multirow{2}{*}{$\begin{array}{l}\text { Entradas } \\
\quad \text { de } \\
\text { capital } \\
\text { neto de } \\
\text { EE.UU. }\end{array}$} & \multicolumn{5}{|c|}{$\begin{array}{l}\text { Distribución por sectores } \\
\text { (porcentaje sobre la inversión acumulada) }\end{array}$} & \multirow{2}{*}{$\begin{array}{c}\text { Porcentaje de } \\
\text { la inversión } \\
\text { acumulada en } \\
\text { España } \\
\text { respecto } \\
\text { a la CEE }\end{array}$} \\
\hline & & & & $\begin{array}{l}\text { Petró- } \\
\text { leo }\end{array}$ & $\begin{array}{c}\text { Fabrica- } \\
\text { ción }\end{array}$ & \begin{tabular}{|l} 
Servicios \\
Públicos
\end{tabular} & $\begin{array}{c}\text { Comer- } \\
\text { cio }\end{array}$ & Otros $^{a}$ & \\
\hline 1929 & 72 & & & & 12,4 & 47,0 & & & 12,37 \\
\hline 1936 & 80 & 8 & & & & 55,0 & & & 16,06 \\
\hline 1943 & 124 & 44 & & & & & & & 13,92 \\
\hline 1949 & & & 19 & & & & & & \\
\hline 1950 & 31 & -93 & 2 & 19,4 & 48,4 & & 6,5 & 22,6 & 4,87 \\
\hline 1951 & 32 & 1 & 1 & 28,1 & 43,9 & 6,2 & 6,2 & 15,6 & 4,27 \\
\hline 1952 & 35 & 3 & 1 & 28,6 & 42,6 & 8,6 & 8,6 & 14,3 & 4,29 \\
\hline 1953 & 40 & 5 & 3 & 30,0 & 40,0 & 7,5 & 7,5 & 15,0 & 4,37 \\
\hline 1954 & 43 & 3 & 1 & 30,2 & 41,9 & 7,0 & 9,3 & 14,0 & 4,23 \\
\hline 1955 & 48 & 5 & 3 & 31,3 & 39,6 & 6,2 & 8,3 & 14,6 & 4,09 \\
\hline 1956 & 48 & 0 & -1 & 31,3 & 39,6 & 6,2 & 8,3 & 14,6 & 3,36 \\
\hline 1957 & 44 & -4 & & 31,8 & 38,6 & 4,5 & 15,9 & 6,8 & 2,62 \\
\hline 1958 & 48 & 4 & & 27,1 & 43,8 & 6,2 & 14,6 & 6,2 & 2,52 \\
\hline 1959 & 53 & 5 & 1 & 28,3 & 45,3 & 5,7 & 13,2 & 5,7 & 2,40 \\
\hline 1960 & 59 & 6 & 2 & 28,8 & 45,8 & 5,1 & 13,5 & 6,8 & 2,23 \\
\hline 1961 & 76 & 17 & 8 & 27,6 & 38,2 & 5,3 & 14,5 & 5,3 & 2,45 \\
\hline 1962 & 90 & 14 & 9 & 30,0 & 40,0 & 4,41 & 5,6 & 4,4 & 2,42 \\
\hline 1963 & 155 & 65 & 28 & 25,8 & 53,5 & 2,6 & 13,5 & 4,5 & 3,45 \\
\hline 1964 & 196 & 41 & 35 & 26,5 & 49,5 & 2,0 & 16,3 & 5,1 & 3,61 \\
\hline 1965 & 275 & 79 & 54 & 23,3 & 51,6 & 2,2 & 16,4 & 6,2 & 4,36 \\
\hline $1966^{b}$ & 408 & 133 & 109 & 26,7 & 47,1 & 2,01 & 8,6 & 5,6 & 5,38 \\
\hline 1967 & 480 & 72 & 70 & 19,4 & 53,5 & 2,1 & 19,6 & 5,6 & 5,68 \\
\hline 1968 & 582 & 102 & 106 & 23,2 & 52,6 & 2,2 & 17,2 & 5,0 & 6,46 \\
\hline 1969 & 607 & 25 & 20 & 19,1 & 52,6 & & & 28,3 & 5,92 \\
\hline 1970 & 737 & 130 & 119 & 19,0 & 51,8 & & & 29,2 & 6,26 \\
\hline 1971 & 778 & 41 & 38 & 16,7 & 54,1 & & & 29,4 & 5,72 \\
\hline 1972 & 910 & 132 & 66 & 16,5 & 53,2 & & & 30,3 & 5,79 \\
\hline 1973 & 1.017 & 107 & 33 & 10,5 & 55,4 & & & 34,2 & 5,27 \\
\hline
\end{tabular}

Fuentes: para 1929-1968, Stanford Research Institute (1972), a partir de datos del Departamento de Comercio de Estados Unidos y del IEME; para 1968-1973, Gallego (1975).

Notas:

${ }^{a}$ Incluye agricultura, minería y fundición y, desde 1969, también comercio y servicios públicos.

${ }^{b}$ El Departamento de Comercio de Estados Unidos ofrece, a pesar de ser la fuente utilizada por el Stanford Research Institute en este cuadro, una cifra diferente para 1966, en concreto 373 millones de dólares. Véase Puig y Álvaro (2003, p. 16). 


\section{CUADRO 2}

\section{DEPENDENCIA COMERCIAL ESPAÑOLA DE ESTADOS UNIDOS}

A. Principales importaciones de Estados Unidos como porcentaje de las importaciones del sector

\begin{tabular}{|l|c|c|c|c|}
\hline & $\mathbf{1 9 3 5}$ & $\mathbf{1 9 5 0}$ & $\mathbf{1 9 6 4}$ & $\mathbf{1 9 7 5}$ \\
\hline Aceites & & & 49,35 & 20,68 \\
\hline Algodón & 58,81 & 52,34 & & 19,03 \\
\hline Aparatos de ciencias y de artes & 29,90 & 29,78 & & 21,55 \\
\hline Automóviles y sus piezas & 30,71 & 30,26 & 10,66 & 10,46 \\
\hline Caucho sin labrar & 20,94 & & & \\
\hline Cereales & & $10,53^{\mathrm{a}}$ & 48,16 & 8,19 \\
\hline Cobre y latón y sus manufacturas & 13,50 & & & \\
\hline Combustibles minerales & 51,41 & 7,39 & 8,64 & 4,49 \\
\hline Grasas y otros productos animales & 10,27 & 20,32 & & \\
\hline Hierro y acero y sus manufacturas & 7,36 & 12,55 & 13,08 & 18,84 \\
\hline Maderas y sus manufacturas & 21,18 & & & 7,93 \\
\hline Maquinaria & 14,81 & 10,78 & 16,75 & 23,01 \\
\hline Material eléctrico & 25,20 & 10,91 & 15,29 & 13,05 \\
\hline Materias para fabricación papel & & & & 24,64 \\
\hline Minerales & 18,09 & & & \\
\hline Papel y cartón & & & & 19,49 \\
\hline Productos fotográficos y cinematográficos & & & & 32,53 \\
\hline Productos químicos & 6,94 & 11,56 & $22,4^{\text {b }}$ & $16,5^{c}$ \\
\hline $\begin{array}{l}\text { Residuos industrias alimenticias, alimentos } \\
\text { para animales }\end{array}$ & & & & \\
\hline Semillas y plantas industriales & & & 63,47 & \\
\hline Tabaco & 5,36 & & 37,64 & 61,26 \\
\hline Transporte aéreo & & 58,42 & & 82,09 \\
\hline
\end{tabular}

Notas: la clasificación por productos en las partidas de las Estadísticas de Comercio difiere de unos años a otros. A continuación se indican las principales partidas incluidas en grupos especialmente heterogéneos o relevantes:

${ }^{a}$ Incluye granos, legumbres y harinas.

${ }^{b}$ Química orgánica y plásticos, éteres y resinas artificiales.

${ }^{c}$ Química orgánica, productos diversos de las industrias químicas y plásticos, éteres y resinas artificiales. 


\section{CUADRO 2 (continuación)}

\section{DEPENDENCIA COMERCIAL ESPAÑOLA DE ESTADOS UNIDOS}

B. Principales exportaciones a Estados Unidos como porcentaje de las exportaciones del sector

\begin{tabular}{|l|r|r|r|l|}
\hline & $\mathbf{1 9 3 5}$ & $\mathbf{1 9 5 0}$ & $\mathbf{1 9 6 4}$ & $\mathbf{1 9 7 5}$ \\
\hline Aceite de oliva & 24,81 & & & \\
\hline Aceite, alcohol y bebidas alcohólicas & $5,25^{\mathrm{a}}$ & 22,41 & & \\
\hline Algodón & & & 10,64 & \\
\hline Artículos de librería y Artes Gráficas & & & 9,25 & 13,59 \\
\hline Calzado & & & 47,11 & 53,42 \\
\hline Caucho y manufacturas & & 9,27 & & 24,04 \\
\hline Coloniales y especias & 30,95 & 20,36 & & \\
\hline Conservas & 16,69 & $51,35^{\mathrm{b}}$ & $34,00^{\mathrm{c}}$ & $29,65^{\mathrm{d}}$ \\
\hline Corcho y sus manufacturas & 13,76 & & & \\
\hline Frutas secas & 16,34 & & & \\
\hline Grasas y aceites & & & 13,38 & \\
\hline Lana & & 92,05 & & \\
\hline Los demás metales y sus aleaciones & & 18,82 & & \\
\hline Manufacturas de cuero & 8,75 & & 14,63 & 29,56 \\
\hline Manufacturas diversas de metales comunes & & & 52,95 & \\
\hline Maquinaria & & & 10,14 & 5,79 \\
\hline $\begin{array}{l}\text { Materias para fabricar papel } \\
\text { (excepto pasta de madera) }\end{array}$ & 86,46 & & & \\
\hline Minerales & 11,11 & 12,04 & & \\
\hline Muebles & & & 45,88 & \\
\hline Oro, plata y platino & & 93,40 & & \\
\hline Prendas de vestir y accesorios & & 49,32 & \\
\hline Productos químicos y farmacéuticos & & $10,42^{\mathrm{f}}$ & 25,82 & \\
\hline $\begin{array}{l}\text { Sal, azufre, tierras y piedras, yesos, } \\
\text { cales y cementos }\end{array}$ & & & \\
\hline Zinc & & & & 73,37 \\
\hline
\end{tabular}

Fuente: Estadística[s] del Comercio Exterior de España (1935), (1950), (1964) y (1975).

Notas: ${ }^{a}$ Vinos. ${ }^{b}$ Varios (conservas, dulces). ${ }^{c}$ Preparados de carnes, preparados de legumbres y hortalizas. ${ }^{d}$ Preparados legumbres y hortalizas. ${ }^{e}$ Abonos químicos. ${ }^{f}$ Química inorgánica. 
nar el valor de los datos oficiales en tiempos de guerra, parece innegable que la neutralidad pro-alemana del régimen franquista alentó varios negocios hispano-norteamericanos importantes, especialmente el petróleo, que contribuyeron a incrementar el poder de Caltex (Standard Oil of California y Texaco) en España y la fortuna de algunos de los empresarios significados, como Juan March ${ }^{18}$. La derrota nazi, en 19441945, volvió a brindar oportunidades a las empresas más familiarizadas con España y a aquéllas cuyos socios supieron jugar con habilidad en el proceso de expropiación de los bienes alemanes en España. Sobre los sectores farmaquímico y electrotécnico, base de la hegemonía industrial germana de la preguerra, se asentarían muchas de las grandes multinacionales americanas ${ }^{19}$. También hubo reveses, como el caso de la Barcelona Traction, la nacionalización negociada de la Compañía Telefónica Nacional de España y la falta de entendimiento entre la Ford y sus socios españoles, que determinaría la salida del fabricante norteamericano en $1954^{20}$.

Las estadísticas de comercio exterior reflejan el interés creciente de los Estados Unidos por España. En los años treinta, la primera potencia mundial se había convertido en su primer socio comercial ${ }^{21}$. Las principales partidas de exportación correspondían a algodón, maderas, petróleo y tabaco, de un lado, y a componentes de automóviles, material eléctrico, maquinaria y productos químicos y farmacéuticos, de otro. Por su parte, los principales bienes importados desde España fueron perdiendo su carácter estrictamente extractivo y agrario de la primera década de siglo, ganando terreno el aceite, las conservas y los abonos químicos, tal como se observa en el Cuadro 2. La dependencia española de los suministros americanos en 1935 era muy elevada en algodón y petróleo, donde más de la mitad de la importación total de estos insumos provenía de Estados Unidos, repuestos de automóviles, y material eléctrico y científico ${ }^{22}$.

La historiografía ha prestado muy poca atención a la influencia de la inversión americana en el milagro económico español, dado que los niveles eran muy bajos en términos absolutos y relativos, pero lo cierto es que los Estados Unidos fueron consolidando una primera posición en inversión directa y en transferencia de tecnología en estos veinticinco años ${ }^{23}$. De acuerdo con los datos agregados disponibles, el

${ }^{18}$ De esta época también data el establecimiento de IBM en España. Sobre Juan March puede encontrarse una breve biografía en Torres (2000, pp.268-277).

19 Este interesante proceso de transnacionalización, supervisado por la Comisión de Expropiación de Bienes Extranjeros del Ministerio de Asuntos Exteriores español, está siendo estudiado por las autoras de este artículo.

${ }^{20}$ Carreras (2003, pp. 57-62).

${ }^{21}$ Viñas et al. (1979, p. 134).

${ }^{22}$ Estadística[s] del Comercio Exterior de España, 1913 y 1935.

${ }^{23}$ Nótese que el establecimiento de Ford a mediados de los años setenta marcó el inicio de una nueva época para la inversión directa americana en España. Para entonces, sin embargo, la inversión europea también había alcanzado niveles muy elevados. Sobre la historiografía predominantemente política-, véase la nota 5. Los economistas aplicados, como Muñoz et. al. (1978), por el contrario, sí prestaron atención a este tema. Recientemente, Tascón ha abordado la cuestión en dos trabajos: Tascón (2002 y 2003). 


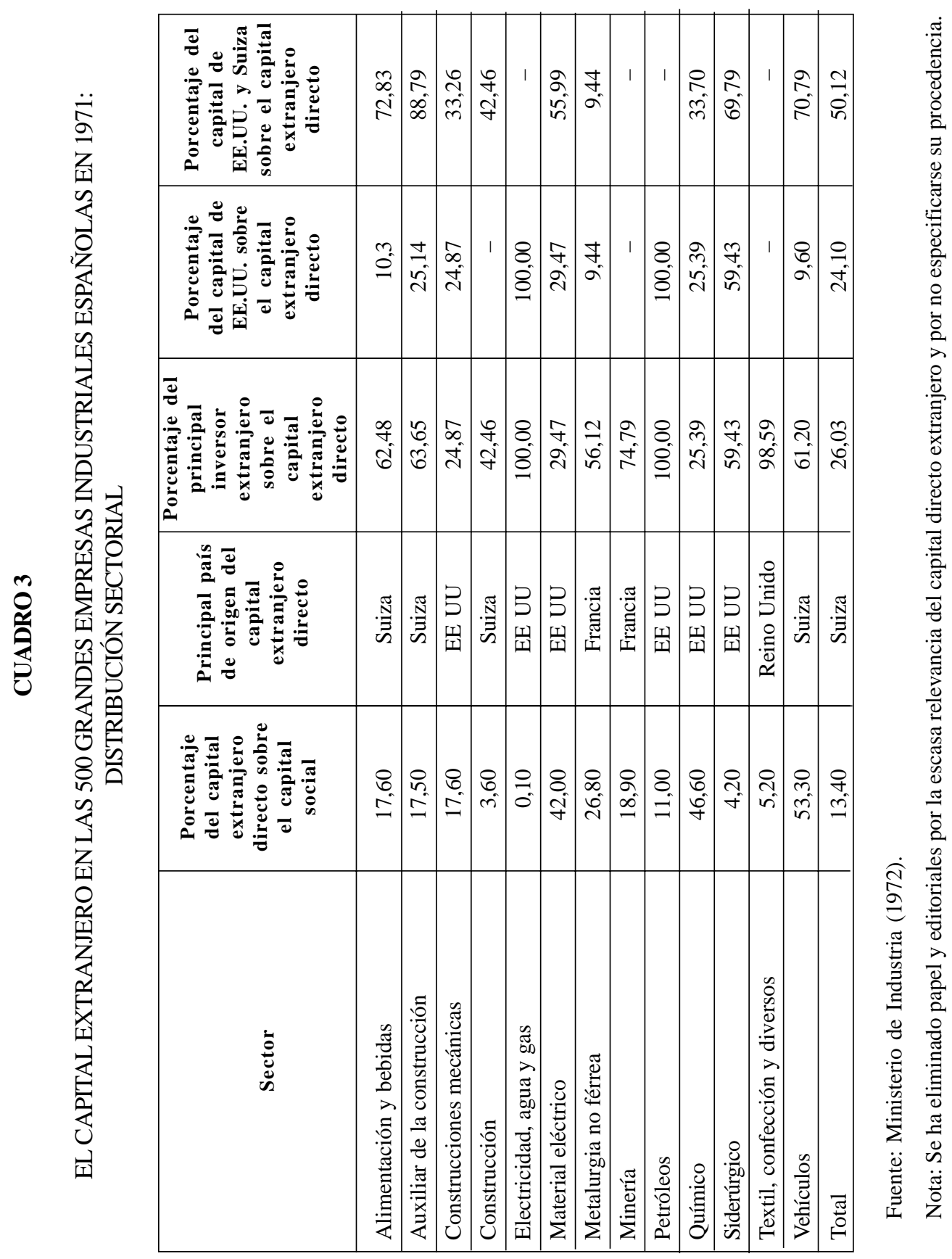




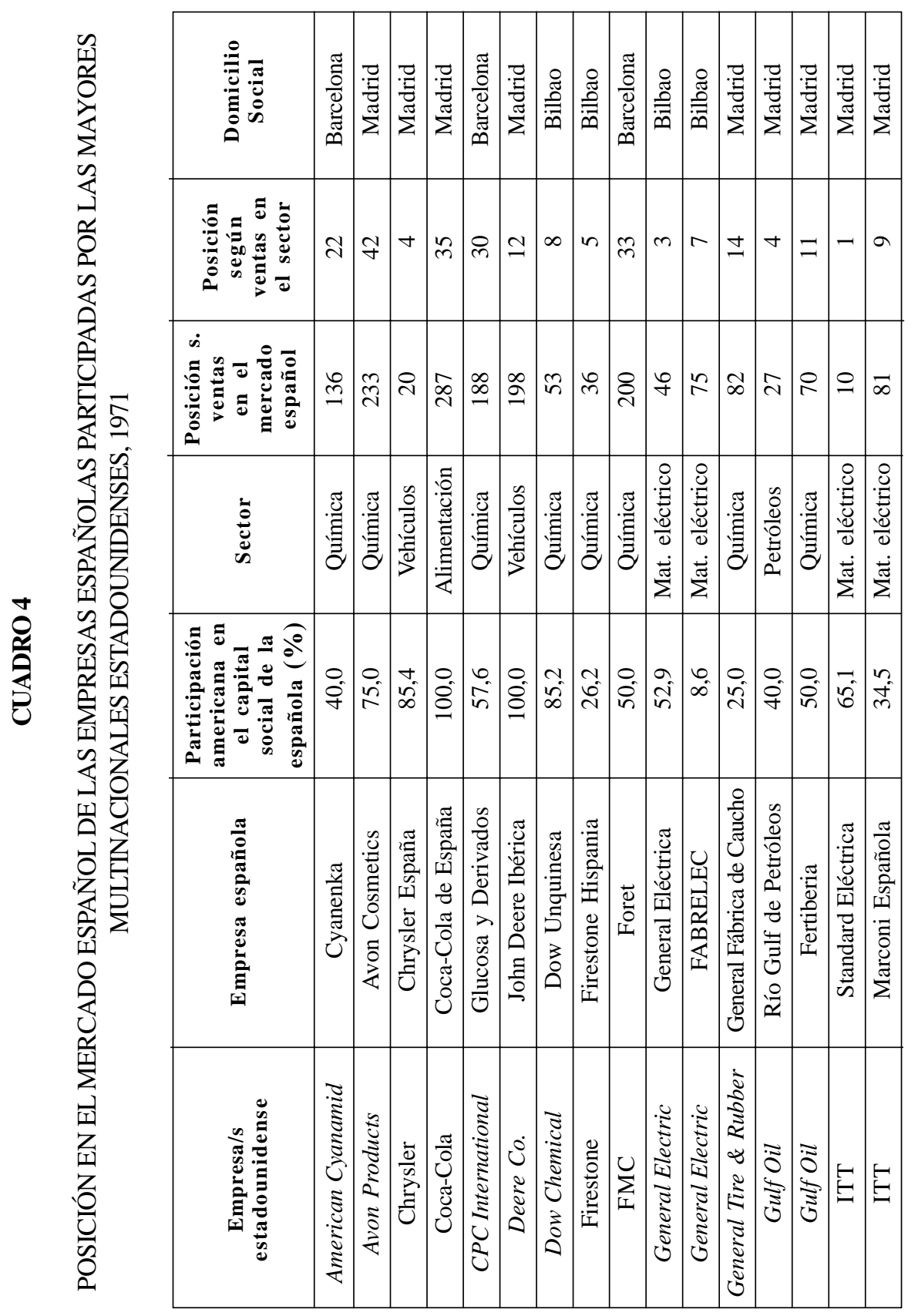


LA GUERRA FRÍA Y LOS EMPRESARIOS ESPAÑOLES: LA ARTICULACIÓN DE LOS INTERESES...

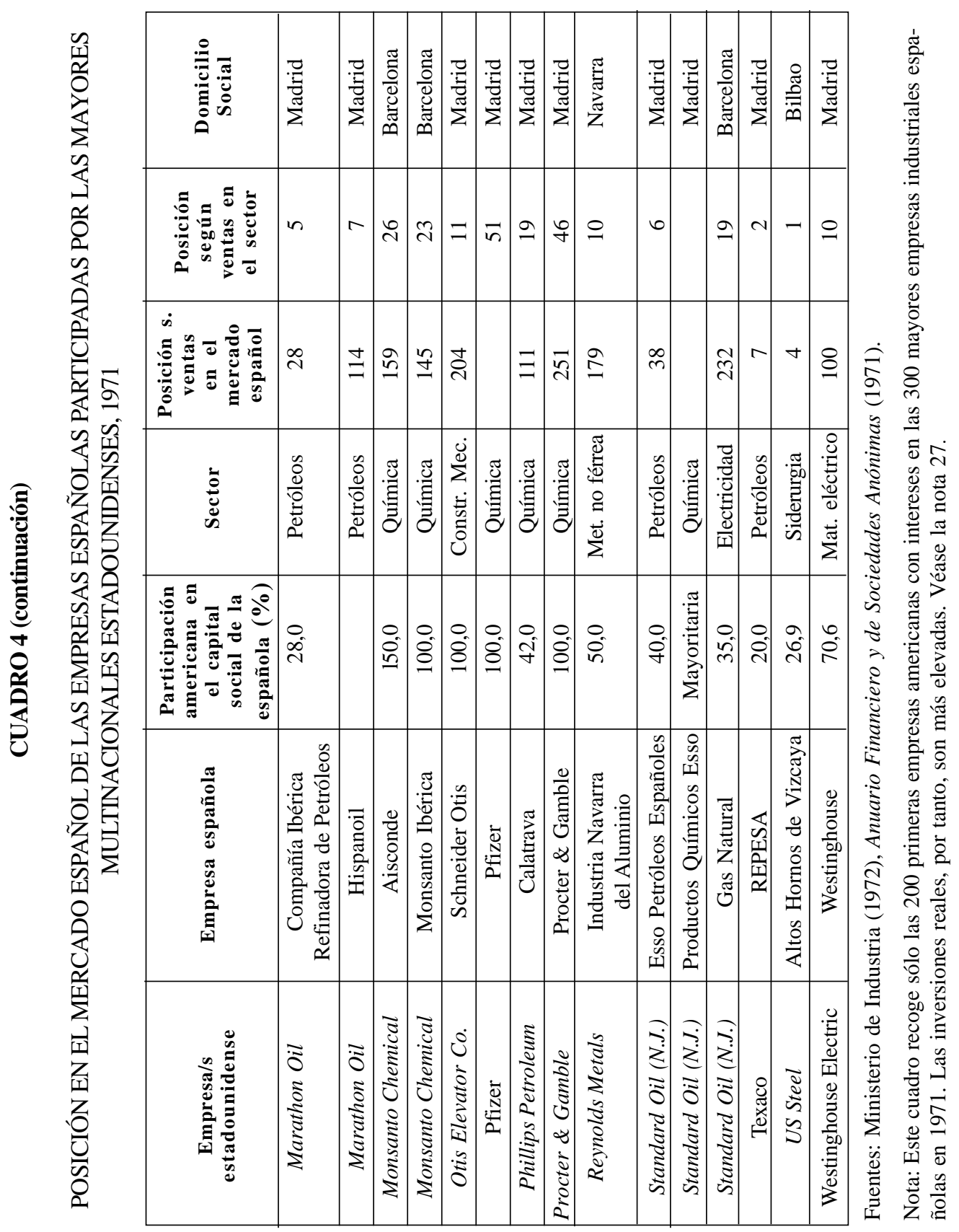


capital americano supuso entre un 50 y un 70 por 100 de la inversión directa total ${ }^{24}$. Los datos sobre patentes y asistencia técnica, complemento natural de la inversión directa, apuntan en la misma dirección ${ }^{25}$. El Cuadro 3 muestra la distribución del capital extranjero en las 500 mayores empresas industriales españolas al comenzar la década de los setenta. Si bien en términos agregados la inversión extranjera sólo representaba el 13 por 100 del capital social de estas empresas, su peso era muy significativo en algunos sectores, como los vehículos, la química, el material eléctrico y la metalurgia no férrea. Por número de empresas, también destacaban alimentación y bebidas y construcciones mecánicas. El origen del capital extranjero se concentraba para casi todas las ramas en Estados Unidos y Suiza ${ }^{26}$. Dado que este último país servía de centro de operaciones para las multinacionales norteamericanas en Europa, es razonable suponer que el capital norteamericano era aún más importante. Como se aprecia en el Cuadro 3, la distribución de las inversiones estadounidenses había sufrido algunos cambios respecto a las primeras décadas del siglo, con un dominio absoluto en los setenta de los sectores del petróleo y la electricidad, y una participación muy significativa en los sectores siderúrgico, de material eléctrico, químico y de construcciones mecánicas. En las industrias de material eléctrico y química coincidían dos circunstancias: el capital extranjero resultaba esencial y Estados Unidos figuraba como principal suministrador. Una imagen de la situación en el mercado de estas empresas y sus socios en 1971 se recoge en el Cuadro 4.

Un análisis más pormenorizado de las empresas americanas con filiales o socios tecnológicos en España entre 1950 y 1975 refleja esta paulatina concentración de los capitales americanos en las actividades indicadas, junto con otros sectores que, por su tamaño, no aparecen en el Cuadro 4, como son los vehículos -General Motors, Chrysler, John Deere- y la alimentación -Borden o Ralston Purina. Lo más interesante es que todas estas empresas ocupaban una posición dominante en los respectivos sectores, gracias a su superioridad tecnológica y también a su capacidad de negociación con las autoridades y los socios españoles ${ }^{27}$. Su actividad

${ }^{24} \mathrm{La}$ diferencia entre una cifra y otra radica en que se incluya como estadounidense la inversión suiza, puesto que numerosas multinacionales americanas operaban desde este último país. Estos datos sólo contabilizan las inversiones mayoritarias, es decir, de más del 50 por ciento del capital social, luego las inversiones reales aún serían mayores. Vid. Muñoz et. al. (1978, pp. 127-130).

${ }^{25}$ Véanse Muñoz et. al. (1978) y Molero (1979).

${ }^{26}$ De hecho, al iniciarse los años setenta, 69 multinacionales estadounidenses participaban, mayoritaria o minoritariamente, en un total de 351 sociedades españolas, siempre según Muñoz et. al. (1978, p. 191). Según la información proporcionada por los directorios estadounidenses de empresas con actividades fuera de sus fronteras y recogida por Puig y Álvaro (2003, p. 17), el número de las sociedades americanas que operaban en España a la altura de 1975 sería 336.

${ }^{27}$ Esto lo tenemos documentado para química, farmacia, telecomunicaciones y electrotecnia. AMAE R-4312 expediente 3, R-4382 expediente 19, R-4308 expediente 1, R-7730, R-7731, R-7737, R-9940 expediente 3, R-9941 expediente 4, R-9945 expediente 2, R-9947 expedientes 1 y 2, R-10.000 expediente 4 . 
exportadora era muy débil, algo coherente con la política económica española y con la estrategia de las multinacionales que actuaban en el país ${ }^{28}$.

El comercio exterior, mientras, mostraba una evolución más errática, ajustada a las trabas y necesidades de la economía española. En las décadas de los cincuenta y sesenta, Estados Unidos continuó siendo el principal socio comercial de España, aunque por detrás del conjunto de la $\mathrm{CEE}^{29}$. Si bien con ciertos cambios en las partidas, en el Cuadro 2 puede observarse cómo la relación entre los dos países se fue consolidando, en cuanto a las importaciones desde Estados Unidos, en torno a dos extremos: los alimentos y primeras materias y la alta tecnología. En cuanto a las importaciones estadounidenses de productos españoles, se fue evolucionando de las primeras materias y alimentos más o menos elaborados a una mayor interrelación, cuya máxima expresión fue el calzado. En 1975 era éste, detrás del zinc, el primer producto de exportación a Estados Unidos, mercado que absorbía más de la mitad del calzado exportado. Las conservas, productos textiles, muebles y algunos metales, especialmente el zinc, constituyeron otras partidas importantes ${ }^{30}$. La mayor complejidad del paisaje empresarial español en los sesenta y setenta encaja con estas pautas.

Pero la influencia estadounidense en España no se limitaba a la inversión industrial y a los intercambios comerciales. Uno de los instrumentos más eficaces de modernización de la gestión de empresas fue la consultoría ${ }^{31}$. Dominado por filiales americanas como Bedaux y MEC (Methods Engineering Council), pero también por otras francesas y belgas, este negocio registró un crecimiento explosivo en los años sesenta. En calidad de socios o de clientes de las grandes consultoras nos encontramos a los principales agentes de la americanización española: el Banco Urquijo, el Instituto Nacional de Industria (INI) y las filiales de multinacionales americanas. La presencia norteamericana fue todavía mayor en las empresas de ingeniería, uno de los vehículos de la transferencia masiva de tecnología que se registró al término de la segunda conflagración mundial, en particular en ámbitos como la industria petroquímica, la energía eléctrica o la ingeniería civil. Entre las empresas pioneras deben mencionarse Foster Wheeler, constructora de la refinería de Escombreras; Lummus, de la que era socio Javier Benjumea; Procon,

${ }^{28}$ Sería éste uno de los extremos más preocupantes para los expertos en inversión extranjera: vid. Gallego (1975). En varios casos hemos comprobado que los inversores norteamericanos se referían al proceso como una «educación del mercado». Significaba esto asegurarse una posición dominante, si no de monopolio, y controlar a proveedores y clientes para garantizar la salida a sus productos. Un ejemplo muy claro es el de la empresa pública Calvo Sotelo y Phillips cuando se creó la petroquímica Calatrava.

${ }^{29}$ Véase Viñas et. al. (1979, pp. 1314 y 1336).

30 Tenemos que explorar aún las relaciones entre los importadores de algodón y los fabricantes textiles, que no hemos incluido entre los sectores pro-americanos por su escaso protagonismo en los foros analizados.

${ }^{31}$ Vid. Egurbide (1976), Molero (1979), y Kipping y Puig (2003a y 2003b). 
en la órbita del Urquijo; y $M c K e e^{32}$. La actividad de las consultoras técnicas fue complementaria de la importante asistencia técnica que recibieron las empresas industriales españolas en la época del desarrollo. La pujante industria de servicios a la empresa incluía asimismo los estudios de mercado y publicidad. Tras el impasse autárquico, y con una fuerte participación o influencia norteamericanas, la industria publicitaria hispana volvió a florecer en los años sesenta ${ }^{33}$. La publicidad sería un instrumento esencial en lo que funcionarios, consultores e inversores estadounidenses llamaron educación económica de los españoles.

Por tanto, al iniciarse la normalización económica española existían ya importantes ventajas e intereses bien representados en la economía del país. Las grandes marcas americanas ya llevaban varias décadas operando en España, en los sectores de tecnología más avanzada y de más rápido crecimiento del momento. A esto se unió un fuerte incremento de las inversiones procedentes de este país en las décadas posteriores, tanto en sectores en los que ya estaban asentadas como en otros con los que contaban con menor presencia. ¿¿Fue esta primera base importante para el desarrollo posterior? ¿Hasta qué punto se asentó la expansión americana del desarrollismo en las relaciones establecidas ya antes de la guerra civil? El desarrollo de los programas oficiales de ayuda técnica firmados con Estados Unidos ofrece algunas claves sobre ello.

\section{EL ENTRAMADO PERSONAL E INSTITUCIONAL DE LAAYUDA TÉCNICA OFICIAL}

El acercamiento político y militar que culminó en la firma de los Pactos de Madrid, y que trajo consigo el programa de ayuda y un incremento significativo de la inversión, no supuso, pues, el principio de la americanización de la economía española, pero sí el inicio de una intensificación. Lo verdaderamente novedoso de esta etapa fue el interés oficial de los Estados Unidos por la economía y los empresarios españoles, un interés que no significaría necesariamente influir en la política económica española, pero sí, como veremos, generar y aprovechar oportunidades de negocio en el país aliado.

Al finalizar la Segunda Guerra Mundial, Estados Unidos se planteó la posibilidad de incluir a España dentro de los países beneficiarios del Plan Marshall. La oposición europea y de su propia opinión pública, muy sensibilizada ante lo que se consideraba el último reducto fascista, dio al traste con las expectativas de las autoridades franquistas, que ya en la segunda mitad de los cuarenta entablaron diferentes gestiones ante diversos organismos americanos con el fin de conse-

\footnotetext{
${ }^{32}$ Véase Molero (1979).

33 Véase IP Mark (2001).
} 
guir ayuda económica. El primer paso en firme hacia la normalización económica de España no llegaría hasta cinco años más tarde, cuando el Senado estadounidense autorizó un crédito a través del Eximbank por una cuantía de 62,5 millones de dólares ${ }^{34}$. El siguiente tendría lugar en septiembre de 1953, con la firma de los Pactos de Madrid entre el ministro Alberto Martín Artajo y el embajador James C. Dunn.

Las negociaciones entre ambos países, así como las características y efectos de los acuerdos, han sido ampliamente debatidos en la historiografía. Si bien se recalca su carácter militar y se insiste en lo limitado de las cuantías recibidas, también se considera como el gran reconocimiento del régimen franquista ante el mundo occidental, que además alivió los estrangulamientos en el sistema productivo derivados de la falta de divisas, facilitó ciertos cambios en la política económica franquista y mejoró el clima de confianza empresarial, favoreciendo el aumento de la inversión nacional y extranjera ${ }^{35}$. Hay que tener en cuenta que los propósitos de Estados Unidos se limitaban al uso eficiente con fines militares del suelo español, para lo que era necesario mejorar las infraestructuras existentes y lograr el apoyo tanto del gobierno local como de la población, ensalzando el modelo de desarrollo económico y social norteamericano ${ }^{36}$. De ahí que más del 40 por 100 de las cuantías recibidas se destinaran a alimentos, para mejorar el nivel de vida de la población, seguidas de algodón -20 por 100-, y material ferroviario, infraestructuras e industrias eléctricas -13 por $100^{37}$.

Junto a la ayuda económica se firmó también un programa de asistencia técnica. Esta ayuda técnica se inscribía en el llamado movimiento de la productividad ${ }^{38}$. A pesar de suponer menos de un uno por ciento de la ayuda económica, se diseñó explícitamente para aumentar la bajísima productividad de las empresas hispa-

\footnotetext{
${ }^{34}$ La mitad de esta cuantía se destinó a la importación de diversas mercancías, destacando las partidas de algodón, trigo y carbón, algo muy acorde con lo que se ha señalado respecto al comercio entre ambos países. Con el resto se financiaron varios proyectos, que englobaban especialmente la minería, las fábricas de fertilizantes y de energía eléctrica y el transporte ferroviario. La identidad de las empresas beneficiarias se recoge en el apartado 5. Para mayor detalle, véase Viñas (1981b).

${ }^{35}$ Véanse notas 5 y 6. También Viñas et. al. (1979), Fanjul (1981), García Delgado (1986), Calvo (2001 y 2002) y la síntesis de Barciela (2000). Calvo señala que el programa contribuyó a crear un clima de confianza empresarial a partir de 1950, pero niega que los Estados Unidos influyeran en la política económica de los gobiernos españoles y, en general, minimiza el impacto institucional de la relación. Como queda patente en este artículo, nosotras corroboramos lo primero, pero diferimos de lo segundo.

36 NARA, Record Group 469, entrada 387, caja 1.

${ }^{37}$ Véase Calvo (2001). Además, una parte de la ayuda económica percibida tenía que ser financiada por el Gobierno español en pesetas, lo que se conoce como la Contrapartida. Estos fondos se destinaron fundamentalmente a infraestructuras. Vid. Fernández de Valderrama (1964).

38 Véase Gil (1967). Sobre las ideas e instrumentos del productivismo, en perspectiva comparada, véase el análisis de Guillén (1994).
} 
nas, facilitar la penetración del capital y la tecnología estadounidenses, y abrir paso a los principios capitalistas en el país. En la España autoritaria de Franco las agencias americanas actuaron, es cierto, con las ventajas derivadas tanto de su experiencia previa en otros países europeos, según la cual el contacto directo con las empresas, asociaciones y universidades americanas era el medio más barato y eficaz para ganarse la confianza de la población europea, como del atraso relativo español, que la hacía más porosa o menos resistente a las ideas foráneas ${ }^{39}$. En cambio, tuvieron que dedicar mucha energía a lidiar con la dictadura y sus representantes más antiliberales, como Suanzes, el autocrático presidente del INI, que trató inicialmente de monopolizar tanto recursos económicos como los proyectos de carácter técnico desarrollados desde la Comisión Nacional de Productividad Industrial (CNPI), el organismo encargado de gestionar la ayuda técnica oficial. Este hecho demoró la puesta en práctica de muchos de esos proyectos, y fue causa de fricciones entre la Embajada de Estados Unidos en Madrid -donde tenían su sede las agencias competentes-, las instituciones españolas que administraban el programa -en los ministerios de Asuntos Exteriores, Industria y Comercio y Educación- y el INI ${ }^{40}$. Finalmente, la acción conjunta de los agentes norteamericanos, de algunos funcionarios españoles, de los sectores empresariales más educados y sensibles a la necesidad de la integración mundial de la economía española, y de instituciones tan consolidadas y tan ambiguas como la Iglesia, sirvió para crear o consolidar en las décadas centrales del siglo XX una serie de círculos modernizadores de la gestión y de la formación empresarial en los centros económicos más dinámicos del país: Madrid, Barcelona y País Vasco ${ }^{41}$.

En buena medida, la ayuda técnica se apoyó en instituciones ya existentes, y en personas, sobre todo, que estaban familiarizadas con los Estados Unidos. Una de esas personas era Fermín de la Sierra ${ }^{42}$. Ingeniero industrial por la Escuela de

${ }^{39}$ NARA, Record Group 469, entrada 387, caja 20.

${ }^{40}$ Si bien el INI se interesó sobre todo por los créditos, mostrando una indiferencia creciente por todo lo relacionado con la ayuda técnica. Las fricciones con los americanos se vieron muy mitigadas por el hecho de que los funcionarios eran uno de los objetivos prioritarios de los programas modernizadores de la gestión. NARA, Record Group 469, entrada 387, caja 18. Las agencias americanas encargadas de la gestión de la ayuda fueron United States Operations Mission (USOM), Foreign Operations Administration (FOA) e International Cooperation Administration (ICA).

${ }^{41}$ En un trabajo pionero, Buesa y Molero (1982) consideraron que el principal impulsor de esta corriente modernizadora había sido el Estado. A nuestro juicio, los empresarios tuvieron un papel bastante más destacado que las instituciones públicas en este proceso.

${ }_{42}$ En la espléndida biblioteca que él mismo legó a la Escuela de Organización Industrial se conserva una de sus pocas obras: Sierra (1953). La crítica a la concentración industrial era uno de los temas recurrentes en la literatura falangista. De la Sierra fue, sin embargo, una persona flexible, que conjugaba la defensa del tejido empresarial tradicional -la pequeña y mediana empresa- con la admiración por el capitalismo americano. Los informes americanos sobre De la Sierra eran siempre elogiosos: NARA, Record Group 469, entrada 387, caja 18. 
Madrid, De la Sierra había trabajado en el Instituto Nacional de Racionalización del Trabajo, creado en 1945 en el seno del Consejo Superior de Investigaciones Científicas. Bajo los auspicios del Instituto, en 1946 y 1947 viajó a los Estados Unidos, donde visitó varias universidades, asociaciones empresariales y empresas. A continuación se le brindó la oportunidad de visitar, en calidad de observador, algunas de las misiones de productividad creadas dentro del programa del Plan Marshall en varios países europeos. En 1952, y desde el Ministerio de Industria, fundó la CNPI, de la cual sería secretario prácticamente hasta su disolución en 1964. En consonancia con el espíritu del régimen, en la Comisión estaban representados todos los ministerios y altas instancias de la Administración, y tanto las corrientes más tayloristas y de eficiencia industrial como las de relaciones humanas $^{43}$. La CNPI era, naturalmente, una de las señales más visibles que la Administración española mandaba al mundo occidental para ser aceptado por el mismo, pues pretendía impulsar y modernizar la empresa privada en España. Respondía también al deseo de los sectores más abiertos y capitalistas de esa Administración de aprovechar la oportunidad única que suponía el apoyo americano, articulado primero a través del crédito del Eximbank y después por medio de la ayuda económica y sobre todo técnica, a partir de 1954. Sería la CNPI precisamente la interlocutora de las agencias de cooperación americanas y el órgano director de los proyectos de carácter técnico más importantes y duraderos que financiaron los Estados Unidos hasta 1963: las comisiones regionales de productividad industrial y la Escuela de Organización Industrial (EOI). Es importante señalar que las comisiones regionales se apoyaban, sobre todo, en empresas privadas locales. Además, se crearon comisiones de estudio en sectores con potencial exportador hacia el mercado americano, como el calzado, o para calibrar los efectos sociales del aumento de la productividad industrial ${ }^{44}$. Salvo en el sector agrario, a cargo directamente el Ministerio de Agricultura, la Comisión se encargaría también de proponer la distribución de los fondos de la ayuda técnica para cada ejercicio, de seleccionar a los miembros de cada una de las expediciones industriales y acadé-

${ }^{43}$ En concreto, los ministerios de Industria y diferentes direcciones generales de éste, Trabajo, Comercio, Educación Nacional, Hacienda, Asuntos Exteriores, Obras Públicas, Ejército, Agricultura, Vivienda, el Instituto Nacional de Industria, el Instituto Nacional de Estadística, el Instituto Nacional de Racionalización del Trabajo, la Cámara de Comercio, Industria y Navegación, la Delegación Nacional de Sindicatos, la Presidencia del Gobierno, el Consejo de Economía Nacional y el Alto Estado Mayor. Vid. Álvaro (2001, pp. 44 y 76). Mientras los temas tayloristas tenían un corte más ingenieril, las relaciones humanas, en cambio, enfatizaban, siguiendo generalmente los criterios de la doctrina católica al respecto, la importancia del bienestar de los trabajadores, dentro y fuera de la empresa, para conseguir mejorar sus rendimientos. Véase al respecto Guillén (1994).

${ }^{44}$ En el caso del calzado, las actividades de la CNPI sirvieron fundamentalmente para propiciar las relaciones comerciales entre ambos países, aumentando significativamente las exportaciones del sector a este país, como se aprecia en el Cuadro 2. Véase Miranda (2002). 
micas que se realizaron en esos años, y de buscar colaboradores idóneos dentro y fuera de la Administración. Casi siempre, la CNPI hubo de actuar con diplomacia, pues era, a fin de cuentas, un mediador entre la Administración americana -que buscaba influir en el disminuido sector privado-, la Administración de un Estado dictatorial -ávida de concentrar la actividad económica en el sector público-, y las iniciativas que la sociedad civil -vasca y catalana sobre todo- había puesto en marcha antes o después de la guerra en las áreas de la productividad o la formación industriales. De la CNPI se esperaba asimismo que contribuyera a desbloquear muchas inversiones americanas en España, poniéndose del lado de la embajada americana, y que facilitara su penetración y desarrollo.

Un análisis cuantitativo de los 143 programas de intercambio llevados a término entre 1954 y 1962 revela que la formación empresarial, en el sentido más amplio, tuvo un papel central: casi la mitad de los mismos y un 40 por ciento de los 972 participantes estuvieron relacionados con la dirección y gestión de empresas $^{45}$. Esto explica que en el seno de la CNPI, y con apoyo financiero y académico directo de las agencias y de universidades estadounidenses, se creara en 1955 la EOI, la primera escuela de negocios a la americana en España y muy orientada por tanto, al principio, hacia la gran empresa, representada en Madrid por el $\mathrm{INI}^{46}$. La EOI contó con una hermana, la Escuela de Administración de Empresas (EAE) que, sin asesores norteamericanos, hubo de apoyarse en diversas instituciones locales, públicas y sobre todo privadas catalanas. La estrella de estas dos escuelas quedaría pronto eclipsada por instituciones privadas como el Instituto Católico de Artes e Industrias -Instituto Católico de Administración y Dirección de Empresas (ICAI-ICADE)-, en Madrid, la Escuela Superior de Administración de Empresas (ESADE) y, sobre todo, el Instituto de Estudios Superiores de Empresa (IESE) en Barcelona. Si los dos primeros nacieron de la colaboración entre empresarios locales y la Compañía de Jesús, el último fue fruto de una asociación parecida

${ }^{45}$ Datos obtenidos a partir de un estudio de la CNPI publicado en Productividad (1963, $\mathrm{n}^{\circ}$ 124, pp. 1-14). Las misiones enviadas a Estados Unidos, salvo temas muy relacionados con la gestión del sector público, estaban formadas tanto por empresarios privados como por funcionarios, y todas ellas tenían en común la visita a las agencias americanas implicadas en los programas, a la importante asociación empresarial American Manufacturers Association (AMA) y a las principales empresas del sector en estudio. A su vuelta existía la obligación, no siempre cumplida, de presentar una memoria explicativa, cuya calidad varía considerablemente de unas expediciones a otras.

${ }^{46} \mathrm{La}$ educación formal de los empresarios es aún un tema poco explorado. Existe un excelente análisis de sus inicios, encargado precisamente por la Fundación Ford a su principal beneficiaria en España, la Sociedad de Estudios y Publicaciones: Frederick y Haberstroh (1969). Véanse también Puig (2003a) y Puig y Fernández (2001a) y (2003). Respecto a la financiación de la CNPI, si bien contaba con aportaciones a cargo del presupuesto general del Estado y con los ingresos derivados de la impartición de cursos en diferentes compañías sobre organización de empresas y, especialmente, de formación de mandos intermedios, más del 50 por ciento correspondía a fondos a cargo del convenio con Estados Unidos. Vid. Álvaro (2001, pp. 57-59). 
entre consultores vascos y catalanes y la Universidad de Navarra, del Opus Dei. En mayor o menor medida, todas las escuelas pioneras se beneficiaron de la ayuda estadounidense, aunque ninguna tanto ni tan directamente como la EOI. Con el tiempo, sin embargo, fue IESE la que más imitó el modelo americano, al vincularse institucionalmente a la mítica Harvard Business School. La americanización de IESE sería paralela a su éxito dentro y fuera de Cataluña, sin duda facilitado por el acceso a la Administración de varios miembros del Opus Dei. Hubo un año mágico para las escuelas de negocios españolas: 1958, el año en que se fundaron o arrancaron todas ellas, coincidiendo con los primeros pasos de la liberalización económica española y con el reconocimiento del fracaso de la política económica del primer franquismo.

Pero donde la ayuda americana se hizo particularmente visible y duradera fue en la Asociación para el Progreso de la Dirección (APD), creada en 1956 por el sociólogo Bernardino Herrero y por varios de los integrantes de uno de los primeros viajes de intercambio a Estados Unidos organizado por la CNPI. Desde el principio, APD centró su misión en los altos directivos de grandes empresas y en el fomento de la profesionalización de la gestión empresarial y la comunicación entre empresarios y directivos ${ }^{47}$. No es extraño que los gestores americanos miraran a APD como a su mejor alumno ${ }^{48}$. La historia de esta asociación constituye además un magnífico punto de partida para abordar la de la inversión americana en España y sus efectos profundos en la sociedad y la economía del país.

Las fundaciones americanas, en concreto la Ford, también estuvieron presentes en la americanización de España. En consonancia con su actividad en el resto de Europa, y empujada por lo incierto de la situación política local, la Ford se centró en cuestiones educativas ${ }^{49}$. Para ello, y tras explorar el terreno, la Fundación optó por apoyar generosamente las actividades intelectuales del Banco Urquijo a través de la Sociedad de Estudios y Publicaciones, que llegó a absorber 35 millones de dólares entre 1957 y 1966, pasando así a ocupar España la duodécima posición como beneficiaria de la Ford, y que colaboró en 1969 en un estudio sobre la educación empresarial en España ${ }^{50}$. La red española de la Fundación Ford incluía también a los herederos de la Institución Libre de Enseñanza y a la Universidad de Navarra, del Opus Dei. Su actuación se hizo más visible en los años setenta, en los campos de la reforma educativa y de la difusión de la lengua inglesa.

\footnotetext{
${ }^{47}$ APD (1970).

${ }^{48}$ NARA, Record Group 469, entrada 387, caja 18.

${ }^{49}$ Según un estudio de 1968 de Fraenkel, uno de los consultores de la Fundación Ford que mejor conoció el país, , los problemas españoles eran cuatro: 1) qué ocurriría después de Franco; 2) la participación política -la historia de España se interpretaba como el fracaso de su población y de sus líderes al no ser capaces de llegar a un consenso, a una convivencia política; 3) el acceso a la educación; 4) la agricultura y el mundo rural. La Ford se centró en el tercer punto. Véanse FFA, informes 004574 y 009024.

${ }^{50}$ Frederick y Haberstroh (1969).
} 
La historia de la ayuda técnica refleja muchas de las transformaciones que se estaban operando en la economía, la política y la sociedad española de esos años. Obviamente, las ideas y las instituciones sostenidas directamente por los fondos norteamericanos no eran los únicos focos de modernidad en España, pero sí los más visibles. Dado el limitado número de personas preparadas y receptivas a este aspecto del capitalismo industrial, se tendió a cooperar, aunque hubo episodios de rivalidad de gran calado, especialmente en los últimos estadios de la ayuda, y relacionados con el cambio que se estaba produciendo en el Gobierno español, especialmente el desembarco de los tecnócratas en la segunda mitad de los cincuenta. Junto a la cooperación, la otra característica de la experiencia española fue la especialización, algo que quedó de manifiesto en el limitado mercado del conocimiento empresarial, de tal modo que las escuelas de negocios, APD y la CNPI se orientaron a colectivos distintos ${ }^{51}$.

\section{LOS CÍRCULOS EMPRESARIALES PRO-AMERICANOS}

El 23 de enero de 1950, Alfred Barth, vicepresidente del Chase National Bank de Nueva York, una de las entidades participantes en la gestión del crédito del Eximbank, se dirigió al abogado Antonio Garrigues Díaz-Cañabate con las siguientes palabras: «Desde ahora en adelante me parece que el caso de España debe quedar en manos de los españoles, porque la puerta ha sido ya abierta y ahora os toca a ti y a tus amigos sacar el mejor partido de ello» ${ }^{52}$. Garrigues, casado con la hija de uno los primeros representantes de ITT en España, Roy A. Walker, había desempeñado un papel importante en el proceso de expropiación de bienes alemanes que el Ministerio de Asuntos Exteriores dirigió al final de la Segunda Guerra Mundial, trabajando como asesor jurídico para las embajadas británica y estadounidense ${ }^{53}$. Esta experiencia aceleraría su carrera como abogado de muchas empresas norteamericanas en España y, ya en los sesenta, como embajador de España en Washington. Los amigos de los americanos a los que se refería el vicepresidente del Chase no tardaron, en efecto, en aprovechar las oportunidades que el apoyo financiero y tecnológico, público y privado, de los Estados Unidos les brindó a partir de 1950. En los veinticinco años siguientes crearían unos círculos que no eran completamente nuevos, como veremos, pero para los que la Guerra Fría actuó de poderoso catalizador. Se constituirían estos círculos alrededor de

\footnotetext{
51 Véase Puig (2003a).

${ }^{52}$ En español en el original: AS R. 594. A. Barth fue uno de los principales asesores de la embajada española en Washington, en las gestiones llevadas a cabo por esta última para obtener algún tipo de ayuda o crédito de las autoridades americanas desde que empezó a esbozarse el Plan Marshall. Véase, por ejemplo, AS R. 603, R. 599, R. 764 y R. 902.

${ }^{53}$ AMAE R-5477, expediente 1.
} 
los intereses de las multinacionales norteamericanas y de sus socios españoles, así como de las instituciones públicas y privadas surgidas alrededor de los programas de ayuda ${ }^{54}$. Todo ello al calor de las mejores expectativas de desarrollo económico de España y las nuevas oportunidades relacionadas con éste, de la aceleración en la internacionalización de las empresas norteamericanas, y de la difusión del modelo americano en Europa.

La exhortación del ejecutivo norteamericano coincidía además con las previsiones que los servicios de inteligencia estadounidenses hicieron ese mismo año sobre la evolución española ${ }^{55}$. Según éstos, la ayuda económica y militar que se estaba debatiendo no bastaría para desencadenar el cambio estructural que España precisaba, pero sí para despertar en la población y en el empresariado deseos de emulación y progreso siguiendo las «recetas» occidentales. En los informes que estos servicios elaboraron durante la década de los cincuenta para el Departamento de Estado, el punto de inflexión en el desarrollo económico y social se situaba en 1950. Pero los análisis posteriores del tejido empresarial hispano no fueron muy alentadores. Era cierto, señalarían en 1954, que los grupos económicos estaban irritados por la competencia de la empresa pública y la mala, cuando no corrupta, gestión de las autoridades económicas, pero el temor a una revuelta social les llevaba a apoyar el régimen totalitario de Franco ${ }^{56}$. El atraso económico y social y la complejidad de la situación política se oponían de este modo a una transformación radical de la cultura económica y laboral del país, el objetivo último de los programas de ayuda técnica. En 1958, poco después de que se promulgara la Ley de Convenios Colectivos y con el proceso de liberalización económica en marcha, los observadores norteamericanos volvían a valorar la naturaleza y función de los empresarios españoles, mientras señalaban que «la economía española se había hecho peligrosamente dependiente de los Estados Unidos» ${ }^{57}$. La bajísima productividad del trabajo en España era fruto de una cultura laboral que garantizaba a los trabajadores empleo seguro,

${ }^{54}$ El concepto de redes de interés ha sido propuesto recientemente para analizar el tejido empresarial español durante la dictadura por Sánchez y Tascón en la introducción a un libro colectivo: Sánchez y Tascón (2003). En ninguno de los capítulos, sin embargo, se aplica el concepto, que queda, pues, pendiente para futuras investigaciones. Otra investigación reciente relacionada con estos conceptos, si bien centrada en la actuación de los grupos empresariales, puede encontrarse en Valdaliso (2002).

${ }^{55}$ OSS (Office of Strategic Services, predecesor de la CIA) 0311 (10.10.1950).

${ }^{56}$ OSS 0483 (28.7.1954).

57 OSS 0579 (7.8.1958, p. 45). En España, como en otros países del sur de Europa, las agencias norteamericanas se afanaban en señalar que sus programas de ayuda no constituían ayuda al desarrollo, sino un medio para combatir la inflación desencadenada por la construcción de las bases y la mayor circulación de bienes. A los observadores americanos les preocupaba, además, el nacionalismo español antiamericano, creciente desde 1957, arraigado tanto en la izquierda como en la derecha del país. Para que en España se produjera un «milagro» similar al italiano o al alemán, apuntaban, era necesaria una ayuda masiva y «un cambio de orientación radical». OSS 0579 (7.8.1958, p. 5). 
y a los empleadores mano de obra barata, sin proporcionar incentivos a ninguno de los dos para mejorar sus rendimientos. El «contrato social del mercado» en el que se fundamentaban la prosperidad y la escasa conflictividad laboral americana tenía, pues, pocas posibilidades de éxito en un marco como éste ${ }^{58}$. Por su parte, y siempre según los servicios de inteligencia, el empresariado prefería la protección al riesgo y era reticente a invertir en cualquier proyecto que no permitiera una amortización rápida y beneficios muy altos ${ }^{59}$. Una protección que no era sólo arancelaria, sino que pasaba por suprimir la libre competencia en el mercado interior echando mano de conexiones personales, controles informales de todos los sectores, así como un manejo hábil de la estructura sindical y de la ineficiencia y falta de coordinación de los ministerios económicos ${ }^{60}$. El paternalismo y el proteccionismo se veían agravados, finalmente, por la hostilidad que los gobiernos habían mostrado hasta entonces hacia el capital privado y por su constante ingerencia en la vida económica del país, origen de disparatados proyectos industriales ${ }^{61}$.

Nuestra reconstrucción de los círculos empresariales pro-americanos revela que, en general, tanto los socios norteamericanos como españoles se acomodaron a este capitalismo castizo descrito por los servicios de inteligencia estadounidenses, cuya información económica solía coincidir con la de las agencias oficiales, cuando no era tributaria de las mismas. Los funcionarios destacados en España defendieron, entre otras muchas cosas, los intereses de las empresas norteamericanas, de forma general -solicitando libertad y garantías para los inversores- y particular -interviniendo en las nacionalizaciones y en los desencuentros más sonoros de los años cuarenta y cincuenta. Pero su misión era bastante más amplia y cautelosa, en la medida en que se trataba de incorporar a España al proyecto atlántico, venciendo la oposición de algunos países europeos y creando un ambiente favorable a la liberalización. El lenguaje de los funcionarios era, pues, bastante más cauto que el de las asociaciones empresariales más influyentes en la política económica exterior de los Estados Unidos, como la National Association of Manufacturers (NAM) ${ }^{62}$. Como también eran cautas, razonablemente, las insti-

${ }^{58}$ Zunz (1998, capítulo 4). Dicho «contrato», muy sucintamente, consistía en un aumento casi simultáneo de la productividad del trabajo, los salarios y los beneficios empresariales.

${ }^{59}$ OSS 0579, p. 44. La traducción es nuestra.

${ }^{60}$ OSS 0579. p. 36.

${ }^{61}$ OSS 0579. En la página 44 se resumía en 9 puntos la situación económica española. El diagnóstico insistía en la necesidad de modernizar la agricultura -sector clave para desencadenar el desarrollo económico, en concordancia por las modernas teorías del desarrollo propugnadas por los economistas de la Guerra Fría-, invertir más en minería, dar prioridad a la empresa privada, liberalizar el mercado de trabajo, devaluar la peseta, mejorar los sistemas de distribución, combatir la evasión fiscal, acabar con las prácticas monopolísticas de los industriales y modernizar los servicios de estadísticas económicas, otro de los pilares de la difusión del modelo americano a Europa tras la guerra mundial y de la OEEC/OCDE.

${ }^{62}$ HML, NAM, serie I, caja 76. 
tuciones españolas más vinculadas a los intereses y a la visión del mundo americanos, como APD.

Los círculos pro-americanos activos durante la dictadura se apoyaban, razonablemente, en los flujos de inversión y de exportación e importación a los que nos hemos referido en los apartados anteriores. Desde 1950, los créditos, contratos, intercambios y demás actividades ligadas a los programas oficiales de la ayuda, económica y técnica, oficial animaron esos flujos, pero, sobre todo, facilitaron la articulación de los intereses de las empresas norteamericanas y de sus socios españoles. Examinaremos los círculos tomando como referencia estos últimos ${ }^{63}$.

Dentro de los círculos más antiguos, que datan de la primera fase de la internacionalización de las grandes empresas estadounidenses, destaca el grupo Urquijo, con una dilatada experiencia como intermediario de la inversión extranjera en España, socio de ITT y de otras multinacionales americanas desde los años veinte, y con una capacidad probada de reconocer oportunidades de negocio en sectores tecnológicamente complejos y de diseñar y ejecutar proyectos en el mercado español ${ }^{64}$. Desde el célebre Pacto de las Jarillas, el Urquijo administraba la mayor parte de los negocios industriales del Banco Hispano Americano, y su actividad era también inseparable de la del Banco Herrero. Propietarios y directivos de las tres entidades desempeñaron un papel sumamente importante en la expropiación de los bienes alemanes y en la gestión de los créditos norteamericanos. El director general del Banco Hispano Americano durante más de 25 años, Andrés Moreno, por ejemplo, fue interlocutor del Gobierno franquista ante políticos y banqueros americanos $^{65}$. Los conocidos desencuentros de esta sociedad con el INI en el campo de la fabricación de automóviles y fertilizantes nitrogenados, entre otros, no impidieron que el Urquijo consolidara su grupo industrial en la primera fase de la dictadura ${ }^{66}$. De talante monárquico y liberal, el grupo hizo gala de una capacidad para reclutar talentos muy notable, y cultivó una división del trabajo tan intensa que pudo contar con negociadores políticos, expertos financieros e industriales con experiencia internacional, y hasta con un nutrido grupo de intelectuales que, como hemos visto,

${ }^{63}$ Una primera y más sintética aproximación a estos círculos se ofrece en Puig y Álvaro (2002). Para un análisis comparativo de los círculos pro-americanos en el sur de Europa, véase Puig y Álvaro (2003).

${ }^{64}$ No existe, que nosotras sepamos, un archivo histórico accesible del Banco Urquijo. Esto hace que la reconstrucción del primer socio español de la inversión industrial extranjera en España se tenga que hacer a través de otros archivos. Una breve biografía de la familia puede encontrarse en Torres (2000, pp. 209-215).

${ }^{65}$ Andrés Moreno, que durante muchos años había trabajado en el Reino Unido, pronto apostó por la liberalización económica española. En 1949 viajó a Estados Unidos para entrevistarse con varios bancos y en ese mismo año recibió a varios congresistas. El Banco Hispano Americano fue uno de los intermediarios del primer crédito estadounidense al régimen franquista de 1950. Torres (2000, pp. 350-353).

${ }^{66}$ San Román (1999), Gómez Mendoza (2000). 
a través de la Sociedad de Estudios y Publicaciones sería interlocutor de la Fundación Ford en los años sesenta. De su mano crecerían la inversión y la transferencia de tecnología norteamericana en los campos de la maquinaria eléctrica, la farmaquímica y el petróleo, así como algunas de las consultoras de ingeniería y empresa de capital español o mixto más importantes del país.

Los caminos del Urquijo se cruzarían de muchas maneras también con los de uno de los empresarios industriales más interesantes de la posguerra, Javier Benjumea, fundador de Abengoa y socio de 3M, Gulf Oil y del futuro grupo Explosivos Río Tinto. Las empresas del Urquijo, así como las de Benjumea, y éste a título individual, figuran entre los primeros socios de APD. Benjumea también promovió, con el concurso de socios norteamericanos y del Urquijo, diversas consultoras técnicas y empresariales, como Lummus Española y Técnicos Especialistas Asociados. En el área de la educación empresarial a la americana, el papel de Benjumea, antiguo alumno de los jesuitas, fue bastante más importante, promoviendo a través del patronato conjunto de ICAI e ICADE la difusión -atemperada por la influencia de la doctrina social católica- del modelo norteamericano en la dirección y organización de empresas.

La banca industrial vasca también supo aprovechar las oportunidades brindadas por el final de la Segunda Guerra Mundial, en particular al bloqueo y posterior subasta de los bienes alemanes, y por la hegemonía norteamericana. Un caso paradigmático fue el del grupo químico Lipperheide. Aunque ajeno a la burguesía industrial vasca, el empresario alemán Federico Lipperheide no tardó en establecer lazos muy fuertes con las principales entidades financieras vizcaínas tras su llegada a Bilbao en 1923. Con el respaldo tecnológico de la IG Farben, durante las guerras española y mundial creó uno de los mayores grupos químicos del país y facilitó los contactos de Altos Hornos de Vizcaya con empresas alemanas. Lipperheide salió airoso del examen exhaustivo al que le sometieron los aliados al concluir la guerra, y no tardó en hallar nuevos socios, como Dow Chemical, que le ayudaron a modernizar sus instalaciones mientras preparaban su desembarco completo en España ${ }^{67}$. El otro sector industrial en el que las empresas alemanas habían sido hegemónicas, el electrotécnico, fue escenario de procesos similares, de los que también supieron hallar nuevas oportunidades, y nuevos socios transatlánticos, los bancos vizcaínos. En la siderurgia tuvo lugar un proceso similar al de la química: Altos Hornos de Vizcaya rompió sus lazos con la industria pesada alemana, asociándose a US Steel. Julio de Arteche, el mítico consejero del Banco de Bilbao, se convertiría al mismo tiempo en una de las cabezas visibles de importantes empresas norteamericanas en España, presidiendo la Constructora Nacional de Maquinaria Eléctrica -filial de Westinghouse- y la Compañía Telefó-

${ }^{67}$ NARA, Record Group 226, entrada 107, caja 3, carpeta 16, expediente 165726. 
nica Nacional de España, cuando aún la influencia de ITT en la misma era notable. La banca vasca, hay que recordarlo, estaba familiarizada con varias multinacionales estadounidenses -General Electric y Firestone- desde los años veinte.

El proceso de bloqueo de los bienes alemanes derivado de la adhesión española a los acuerdos de Bretton Woods sirvió asimismo para que la familia Garrigues se convirtiera en una figura de referencia entre las agencias y las empresas norteamericanas y los empresarios españoles interesados en Estados Unidos. Es significativo que a principios de los años setenta, Antonio Garrigues Walker, hijo del interlocutor del vicepresidente del Chase y embajador de España en Washington, perteneciera a los consejos de administración de ITT, General Electric, Westinghouse, US Steel y Avon, además de Colgate-Palmolive, Cabot, IBM, PepsiCola, Ford -desde 1973-, y varios hoteles y compañías de seguros e inmobiliarias $^{68}$. En 1965, varios miembros de la familia Garrigues fundaron la Liga Financiera, una consultora especializada en inversión extranjera en España.

La asociación con multinacionales norteamericanas está en el origen de otros grupos relevantes del momento, como Barreiros, ligado a Chrysler; la familia Carulla, fundadora de Gallina Blanca con Ralston Purina y Borden Foods; y la familia Sáinz de Vicuña, socia de Colgate Palmolive, Avon y Coca-Cola, entre otras ${ }^{69}$. El nacionalismo económico vigente, protector del mercado interior y restrictivo con la inversión extranjera, actuó de acicate de estas y otras asociaciones, que en muchos casos desembocaron -ya en plena liberalización- en la venta integral de empresas españolas a multinacionales. En el ámbito de la publicidad hubo numerosas alianzas, como la de Alas y J. Walter Thompson en 1963, pionera de un proceso que se intensificaría en los setenta.

Pero la actividad económica más emblemática de la Guerra Fría y de la hegemonía norteamericana es, sin duda, la industria del petróleo. Aunque algunas petroleras estadounidenses habían explorado el mercado español en los años veinte, fue en las guerras española y mundial cuando el petróleo y las petroleras cobraron importancia. A ellas está asociado el origen de grupos empresariales de la dictadura como March y Fierro. Pero las grandes compañías refinadoras y petroquímicas norteamericanas actuaron con todos los grupos industriales relevantes del momento: Cepsa -con experiencia en el sector del refino desde 1929-, el INI, el Urquijo, Benjumea y la banca vasca, además de Barreiros. Sus relaciones, igual que sus éxitos y fracasos, estuvieron condicionados por la política reguladora del sector, que puso muchos obstáculos a la creación de refinerías y complejos petroquímicos en los centros industriales del país ${ }^{70}$. Así, Caltex construyó con el

${ }^{68} \mathrm{El}$ poder de la familia Garrigues ya fue resaltado a finales de los años 70 desde la economía aplicada. Vid. Muñoz et. al. (1978, pp. 422-424).

${ }^{69}$ Sobre la alianza entre Chrysler y Barreiros, ver García y Santos (2001).

${ }^{70}$ Lo que sigue procede de Puig (2003b, capítulo 7). 
INI y Cepsa la refinería de Repesa en 1949. El concurso para la refinería de Coruña, Petroliber, se adjudicó al consorcio formado por Alfonso Fierro, la futura Marathon Oil y el propio Estado español a través del Banco Exterior y la Dirección General del Patrimonio. La construcción y gestión de la refinería y el complejo petroquímico de Huelva corrió a cargo de Gulf Oil y Río Tinto, gracias a la intermediación de su presidente, Benjumea, y de Jack Fitzpatrick. La refinería de Castellón fue adjudicada a la Standard Oil (Esso) y Banesto. Y la de Gibraltar, a Cepsa, asociada a Continental Oil (Conoco) y American Oil (Amoco) para construir las filiales petroquímicas. Los otros tres grandes proyectos de la época, Puertollano, Petronor -en Bilbao- y Entasa -en Tarragona-, corrieron a cargo, respectivamente, del INI -a través de su filial Calvo Sotelo-; de un consorcio formado por Gulf, la banca vasca, Campsa y Río Tinto, y el INI; y de una asociación entre el INI, Chevron y Texaco -sucesoras de Caltex-, Explosivos Río Tinto y varios bancos industriales. El proyecto, muy deseado, de crear una refinería en Bilbao convocó a los grupos Garrigues -con Occidental Petroleum-, Barreiros -con Mobil Oil- y Fierro - con Chevron y Shell- y al consorcio formado por la empresa de ingeniería Sener, la banca vasca y Gulf. Finalmente, la Calvo Sotelo creó el primer centro petroquímico en España de la mano de Halcon y Phillips Petroleum, entre otros. Es significativo que las petroleras europeas se lamentaran de las relaciones privilegiadas de sus rivales norteamericanas con los ministerios españoles.

Más vinculada todavía a la Guerra Fría estuvo la construcción de las bases militares. Se trata de un capítulo apenas estudiado de la historia económica y empresarial española, en el que participaron, que nosotras sepamos, empresas como Agromán -de la familia Aguirre-, Abengoa, Rivière y Roca, entre otras muchas. En los tres primeros casos hay pruebas de que estuvieron relacionadas con el entramado de instituciones públicas y privadas alimentadas por la ayuda técnica. Como Roca, las tres estaban ligadas tecnológicamente a grupos empresariales estadounidenses. En las comisiones regionales de la CNPI, administradora oficial de la ayuda técnica en España, hemos identificado empresas particularmente activas y ligadas a la inversión directa, a los créditos oficiales o a las programas de intercambio norteamericanos: la Maquinaria Terrestre y Marítima, Rivière, General Electric, Dow Chemical y Altos Hornos de Vizcaya, socia de US Steel.

Desde 1950, los créditos oficiales norteamericanos -canalizados a través del Eximbank y el Fondo de Préstamos para el Desarrollo- sirvieron asimismo para fortalecer los círculos pro-americanos objeto de nuestro estudio. Del primer crédito, anterior a los Pactos de Madrid, se beneficiaron especialmente empresas de los sectores de la minería, fertilizantes, energía eléctrica y transporte ferroviario: Duro Felguera, Fluoruros, Río Tinto, Hidro-Nitro, Sociedad Ibérica del Nitrógeno, Potasas Españolas, Altos Hornos de Vizcaya, Encaso, Central Siderúrgica, Endesa, Unesa, Unión Eléctrica Madrileña, Renfe, Cepsa, Agromán y Elcano. Los créditos se repartirían entre los sectores eléctrico -Iberduero, Endesa, Unión Eléctrica 
Madrileña, Térmica Soto de Rivera, Langreo e Hidrola-, siderúrgico -Altos Hornos y ENSIDESA- y de transportes -Renfe e Iberia. En cuanto a los créditos del Fondo, considerablemente menores, fueron destinados a Renfe, Isodel y Unión Eléctrica Madrileña ${ }^{71}$.

Para completar el cuadro trazado faltan dos influyentes instituciones privadas durante la guerra fría: la Fundación Ford y la asociación empresarial APD. Ya se ha señalado el vínculo del grupo Urquijo con la Fundación Ford, así como con otras figuras empresariales, nacionales y extranjeras, con las que la Ford entraría así en contacto. También se ha hecho referencia a diversos miembros de APD, asociación a la que pertenecieron buena parte de las compañías y los dirigentes más dinámicos, y pragmáticos, de este período. Entre ellos figuró el presidente de esta asociación durante una década, José María Aguirre Gonzalo, quien también ocupó altos cargos en Agromán y Banesto. Las escuelas de negocios de cuño americano, por su parte, actuaron como centros de formación y foros de encuentro de numerosos miembros de los círculos pro-americanos.

Desde un punto de vista regional, el peso de las personas, empresas e instituciones radicadas en Madrid era muy elevado, algo que cabe atribuir tanto a la política económica franquista como a la concentración de la intervención oficial norteamericana y de las entidades financieras españolas en la capital, así como a la construcción de una base militar en sus cercanías ${ }^{72}$. Si bien eran Madrid y Barcelona los núcleos que concentraban las inversiones productivas estadounidenses al iniciarse la década de los cincuenta, Bilbao se encontraba también entre las zonas más beneficiadas veinte años más tarde. A pesar de que el grueso de las empresas americanas se situara en la capital, la vida asociativa ligada a la inversión directa y a las ideas y técnicas difundidas por los programas de ayuda técnica floreció en las tres regiones. En Madrid, donde la tradición industrial era débil, la influencia norteamericana se hizo especialmente visible en la industrialización del Corredor del Henares y de Villaverde, por ejemplo, así como en la mejora de la red de comunicaciones terrestres y aéreas. También en el crecimiento del número de filiales de multinacionales norteamericanas, que consolidó a Madrid como capital de la inversión americana en España, en la expansión de la colonia americana, eficaz demandante y difusora de la cultura estadounidense, en la construcción de barrios nuevos y, sobre todo, en la proliferación de empresas de servicios a la empresa y de instituciones, públicas y privadas, relacionadas con los programas de ayuda. Una tradición industrial débil significaba además mayor permeabilidad a las ideas foráneas y una mayor disposición a asociarse con empresas extranjeras sin

\footnotetext{
${ }^{71}$ Véase Álvaro (2001)

${ }^{72}$ El impacto de la base de Torrejón de Ardoz sobre la vida económica y social de la región es algo que merece ser estudiado.
} 
intervenir en su gestión ${ }^{73}$. Lo primero quedó reflejado en la recepción de los modelos norteamericanos de organización del trabajo y de la empresa y en la actividad de las consultoras de empresa ${ }^{74}$. Lo segundo está documentado por los anuarios financieros y por algunos estudios de caso realizados hasta ahora, y contrasta con el patrón de la inversión americana en Barcelona y en el País Vasco, donde hubo más propensión a crear empresas mixtas, de vida más o menos larga.

\section{CONCLUSIONES}

Construidos sobre la base de antiguas relaciones con multinacionales norteamericanas o de nuevas oportunidades creadas durante o después de la Segunda Guerra Mundial, los círculos empresariales pro-americanos constituyen, a nuestro juicio, el resultado más palpable y duradero del proceso de articulación de los intereses económicos de Estados Unidos en España que tuvo lugar durante la primera fase de la Guerra Fría. El entramado de la ayuda técnica, entendida ésta como el conjunto de programas oficiales, contratos e inversiones privadas que sirvieron para transferir a España las técnicas de producción y organización asociadas al modelo americano, sirvió tanto a las compañías norteamericanas interesadas en el mercado español como a los empresarios españoles situados en la vanguardia de la segunda revolución industrial o sensibles a las instituciones propias de la sociedad de consumo. De este modo, los efectos de la Guerra Fría del apoyo económico y técnico brindado por los Estados Unidos a España como consecuencia de la misma- trascendieron el productivismo -muy difícil de implantar en un país con el marco institucional del franquismo- y contribuyeron a que los empresarios de ambos lados del Atlántico aprovecharan un conjunto de cir-

${ }^{73}$ El nivel de burocratización de las empresas en zonas de tradición industrial más débil suele ser mayor. Esta variable es significativa del grado de profesionalización de la gestión de la empresa, germen de la empresa moderna. Se considera que altos niveles de burocratización facilitan la entrada de nuevas técnicas y métodos de organización, al disminuir el peso de la tradición familiar y fomentar la entrada de directivos más capacitados. En el caso español, en líneas generales, este proceso tuvo lugar simultáneamente a la expansión de las escuelas de comercio y de las consultoras, muy americanizadas como se ha expuesto. De ahí que sea previsible que la influencia estadounidense fuera especialmente intensa en aquellas zonas en las que el grado de burocratización de las compañías privadas fuera más alto, como era el caso de Madrid. Un estudio pionero sobre propietarios y directivos de las empresas españolas puede encontrarse en Miguel y Linz (1964).

${ }^{74}$ En España se siguió el patrón europeo, es decir, la adaptación de las técnicas americanas al entorno institucional local, siendo más adecuado hablar de hibridación en lugar de imitación. Diversos casos pueden seguirse en Puig y Fernández (2001), Álvaro (en prensa) y Kipping y Puig (2003a y 2003b). 
cunstancias excepcionales hasta finales de los cincuenta: el fin de la hegemonía industrial germana en Europa, la necesidad por parte de Estados Unidos de nuevos aliados en el Mediterráneo, la debilidad de los lazos económicos entre España y sus socios europeos tradicionales, y el colapso de la economía española como resultado del autarquismo. Igual que la ayuda económica no tuvo por objeto promover el desarrollo económico español, y mucho menos americanizar la sociedad española, sino exponer a ésta -y muy en particular a sus empresarios- a la influencia del exterior, asegurando el apoyo del país a la causa de la Guerra Fría, la asistencia técnica -oficial o no oficial- no fue un recetario taylorista, sino un instrumento sutil de liberalización y de ampliación del horizonte comercial de los inversores, exportadores e importadores norteamericanos. La extrema dependencia tecnológica que los empresarios españoles han mantenido durante toda la edad contemporánea hizo todavía más eficaz el programa. En el contexto de anemia institucional de la dictadura, muchas de las ideas y actividades patrocinadas o subvencionadas por los fondos norteamericanos fueron acogidas positivamente por la élite -vieja o nueva- económica y social. Con mayor entusiasmo aún fueron recibidos, desde el final de la Guerra Mundial, los créditos y oportunidades de negocio. Y es que los amigos a los que se refería el vicepresidente del Chase cruzaron, efectivamente, el umbral de esa puerta que la Guerra Fría abrió en la sofocante morada de los españoles en 1950. Para sus socios norteamericanos, esa puerta daba acceso a un mercado europeo poco desarrollado, pero lleno de posibilidades.

\section{FUENTES}

Archivo del Ministerio de Asuntos Exteriores (AMAE), Madrid.

Serie renovada, R-4312 expediente 3, R-4382 expediente 19, R-4308 expediente 1, R-5477 expediente 1, R-7730, R-7731, R-7737, R-9940 expediente 3, R-9941 expediente 4, R9945 expediente 2, R-9947 expedientes 1 y 2, R-10.000 expediente 4.

Archivo General de la Administración (AGA), Alcalá de Henares. Comercio, caja 36.572.

Archivo Suanzes (AS), Madrid.

R 594, R. 603, R. 599, R. 764 y R. 902.

Asociación para el Progreso de la Dirección (APD), Madrid.

Ford Foundation Archives (FFA), Nueva York.

Foundation Activities in Spain, 1968-1976.

Hagley Museum and Library (HML), Wilmington, Delaware.

National Association of Manufacturers (NAM) Papers, access 1411, series I, boxes 76, 77, 78; series IV, boxes 22, 23.

E. De Luca Papers, access 2190, boxes 1, 2. 
National Archives and Record Administration (NARA), Washington.

Record Group 469, entry 387, boxes 1, 2, 18, 20, 31.

Record Group 226, entry 107, box 3.

Office of Strategic Services (OSS)-State Department Intelligence and Research Reports, Europe, 1950-1961.

Microfilm, Biblioteca de la Universidad de Glasgow (History CR20).

Spain, reports 0311, 0483, 0579.

\section{BIBLIOGRAFÍA}

Álvaro, A. (2001): «Estados Unidos y la modernización de la economía española. El régimen y los empresarios españoles ante la Ayuda Técnica: la Comisión Nacional de Productividad Industrial, 1945-1964». Madrid: Facultad de Ciencias Económicas y Empresariales de la Universidad Complutense de Madrid, trabajo de investigación doctoral inédito.

- (en prensa): «Changing Patterns of Ownership and Labor Management under Changing Institutional Regimes: The Case of Telefónica in Spain, 1924-1970», en R. Hjerppe, E. Vaara, A. Kuusterä y S. Fellman (eds.), Historical Perspectives on Corporate Governance: Reflections on Ownership, Participation and Different Modes of Organizing. Helsinki: Universidad de Helsinki.

Amdam, R. P. (ed.), (1996): Management, Education and Competitiveness: Europe, Japan and the United States. London-New York: Routledge.

Anuario financiero y de sociedades anónimas. Madrid.

Asociación para el Progreso de la Dirección (1970): Informe de sus actividades. Madrid.

BARCiela, C. (2000): La ayuda americana a España (1953-1963). Alicante: Biblioteca virtual Miguel de Cervantes, Universidad de Alicante (http://www.cervantesvirtual.com).

Barjot, D. (dir.), (2002): Catching up with America. Productivity Missions and the Diffusion of American Economic and Technological Influence After the Second World War. París: Presses de l'Université de Paris-Sorbonne.

- y RéveILlard, C. (dirs.), (2002): L'américanisation de l'Europe occidentale au XXe siècle. Mythe et réalité. París: Presses de l'Université de Paris-Sorbonne.

—, Lescent-Giles, I. y Ferriere le VAyer, M. (eds.), (2002): Americanisation in $20^{\text {th }}$ century Europe: Economics, Culture, Politics. Lille: CRHENO-Université Charles-de-Gaulle-Lille 3.

Becker, W. y McClenaham, W. (2003): The Market, the State, and the Export-Import Bank of the United States, 1934-2000. Cambridge: Cambridge University Press.

Buesa, M. y Molero, J. (1982): «Cambio técnico y procesos de trabajo: una aproximación al papel del Estado en la introducción de los métodos de la organización científica del trabajo en la economía española durante los años cincuenta». Revista de Trabajo 6768, pp. 249-268.

Calvo, O. (2001): «ßBienvenido, Míster Marshall! La Ayuda Económica americana y la economía española en la década de 1950». Revista de Historia Económica XIX, nº extraordinario, pp. 253-275.

- (2002): «The Political Economy of Conditional Foreign Aid to Spain, 1950-1963». Londres: London School of Economics, tesis doctoral inédita. 
Carreras, A. (2003): «La gran empresa durante el primer franquismo: un momento fundamental en la historia del capitalismo español», en G. Sánchez y J. Tascón (eds.), Los empresarios de Franco. Política y economía en España, 1936-1957. Barcelona: Crítica, pp. 47-65.

Delgado, L. (2002): «Les Etats-Unis et l'Espagne, 1945-1975: une liaison stratégique avec des effets secondaires», en D. Barjot y C. Réveillard (dirs.), L'américanisation de l'Europe occidentale au XXe siècle. Mythe et réalité, París: Presses de l’Université de Paris-Sorbonne, pp. 121-137.

DjeLIC, M. (1998): Exporting the American Model. The Postwar Transformation of European Business. Oxford: Oxford University Press.

EDWARDS, J. (1994): Anglo-American Relations and the Franco Question 1945-1955. Oxford: Oxford University Press.

Egurbide, P. (1976): «El «consulting» en España». Información Comercial Española 133, pp. 133-137.

Engwall, L. y Zamagni, V. (eds.) (1998): Management Education in Historical Perspective. Manchester: Manchester University Press.

Estadísticas del Comercio Exterior de España. Madrid: Dirección General de Aduanas.

FAnsul, E. (1981): «El papel de la ayuda americana en la economía española, 1951-1957». Información Comercial Española 577, pp. 159-165.

FernándeZ de Valderrama, G. (1964): «España-USA, 1953-1964». Economía Financiera 6.

Ford Foundation (1954-1968): Annual Reports. Nueva York.

Frederick, W. C. y Haberstroh, C. J. (1969): La enseñanza de dirección de empresas en España. Management Education in Spain. Madrid: Moneda y Crédito.

Gallego, M. (1975): «Las inversiones de multinacionales USA en España». Economía Industrial 133, pp. 31-45.

García Delgado, J. L. (1986): «Crecimiento industrial y cambio en la política española en el decenio de 1950. Guía para un análisis». Hacienda Pública Española 100, pp. 287-296.

García, J. L. y SAntos, M. (2001): ¡Es un motor español! : historia empresarial de Barreiros. Madrid: Síntesis.

Garthoff, R. (1985): Détente and Confrontation : American-Soviet Relations from Nixon to Reagan. Washington D.C.: Brookings Institution.

Gemelli, G. (1996): «American influence on European management education. The role of the Ford Foundation», en R.P. Amdam (ed.), Management, Education and Competitiveness. Europe, Japan and the United States. Londres: Routledge, pp. 38-67.

- (ed.), (1998): The Ford Foundation and Europe (1950s-1970s). Cross-Fertilization of Learning in Social Science and Management. Bruselas: European Interuniversity Press.

Gil Peláez, J. (1967): «Los EE.UU. en el movimiento español de la productividad». Información Comercial Española 409, pp. 145-148.

Gómez Mendoza, A. (2000): De mitos y milagros. El Instituto Nacional de la Autarquía. Barcelona: Edicions de la Universitat de Barcelona - Fundación Duques de Soria.

Gourvish, T. y Tiratsoo, N. (eds.), (1998): Missionaries and Managers: American Influences on European Management Education, 1945-1969. Manchester: Manchester University Press.

Guillén, M. (1994): Models of Management. Work, Authority, and Organization in a Comparative Perspective. Chicago: Chicago University Press. 
GuiRAo, F. (1998): Spain and the Reconstruction of Western Europe, 1945-1957. Challenge and Response. Oxford: Macmillan.

Hogan, M. (1987): The Marshall Plan: America, Britain and the Reconstruction of Western Europe. Cambridge: Cambridge University Press.

IP MARK (2001): «Un siglo de marketing y publicidad en España», 566, $\mathrm{n}^{\circ}$ extraordinario. JARQUE Í̃̃IGUEZ, A. (1998): «Queremos esas bases». El acercamiento de Estados Unidos a la España de Franco. Alcalá de Henares: Centro de Estudios Norteamericanos de la Universidad de Alcalá.

Kipping, M. y BJarnar, O. (eds.), (1998): The Americanisation of European Business: The Marshall Plan and the Transfer of US Management Models. London: Routledge.

- y Puig, N. (2003a): «De la teoría a la práctica: las consultoras y la organización de empresas en perspectiva histórica», en C. Erro (dir.), Historia empresarial. Pasado, presente y retos del futuro. Barcelona: Ariel, pp. 101-131.

- (2003b): «Entre influencias internacionales y tradiciones nacionales: las consultoras de empresa en la España del siglo XX». Cuadernos de Economía y Dirección de la Empresa 17 (octubre-diciembre), pp. 105-137.

Kipping, M. y Tiratsoo, N. (eds.), (2002): Americanisation in 20 $0^{\text {th }}$ Century Europe: Business, Culture, Politics. Lille: CRHENO-Université Charles-de-Gaulle-Lille 3.

LIEDTKE, B.(1998): Embracing a Dictatorship. US Relations with Spain, 1945-1953. London: St. Martin's Press-Macmillan.

MAIER, C. (1987): «The politics of productivity: foundations of American international economic policy after WWII», en C. Maier (ed.), In Search of Stability: Explorations in Historical Political Economy. Cambridge: Cambridge University Press, pp. 121-152.

MarquinA, A. (1986): España en la política de seguridad occidental 1939-1986. Madrid: Ediciones Ejército.

McGlade, J. (2000): «Americanization: Ideology or Process? The Case of the United States Technical Assistance and Productivity Programme», en J. Zeitlin y G. Harrigel (eds.), Americanization and its limits. Reworking US technology and management in post-war Europe and Japan. Oxford: Oxford University Press, pp. 53-75.

- (2001): "Containment Policies and the Re-Shaping of Western Business», comunicación presentada a $5^{\text {th }}$ European Business History Association Annual Congress, Oslo, 31 agosto - 1 septiembre.

Miguel, A. y Linz, J. (1964): «Características estructurales de las empresas en España: tecnificación y burocracia», Racionalización 94, pp. 1-11, 97-104, 193-208, 289-296.

Ministerio De Industria (1972): Las 300 grandes empresas industriales en 1971. Madrid.

Miranda, J. A. (2002): «La Comisión Nacional de Productividad Industrial y la «Americanización» de la industria del calzado en España», comunicación presentada al Seminario La americanización en España: 50 años de influencia económica y social, Universidad Complutense de Madrid, 12-13 septiembre.

Molero, J. (1979): «Las empresas de ingeniería». Información Comercial Española 59, pp. 59-71.

Muñoz, J., RoldÁn, S. y SerRAno, Á. (1978): La internacionalización del capital en España, 1959-1977. Madrid: Edicusa.

Niño, A. (coord.), (2003): «Cincuenta años de relaciones entre España y Estados Unidos». Cuadernos de Historia Contemporánea, dossier. 
Oromí, J. M. (1957): Memoria histórico-informativa de los Acuerdos entre España y Estados Unidos. Madrid: Ministerio de Asuntos Exteriores y Cámara Americana de Comercio.

Portero, F. (1989): Franco aislado, la cuestión española (1945-1950). Madrid: Aguilar.

Productividad, Boletín de información de la Comisión Nacional de Productividad Industrial (1953-1965). Madrid.

Puig, N. (2003a): «Educating Spanish Managers: the United States, Modernizing Networks, and Business Schools in Spain, 1950-1975», en R.P. Amdam, R. Kvalshaugen y E. Larsen (eds.), Inside the Business Schools: The Content of European Management Education. Oslo: Abstrakt Press, pp. 58-86.

- (2003b): Bayer, Cepsa, Puig, Repsol, Schering y La Seda. Constructores de la química española. Madrid: LID Editorial Empresarial.

- y Álvaro, A. (2002): «Estados Unidos y la modernización de los empresarios españoles, 1950-1975: un estudio preliminar». Historia del Presente 1, pp. 8-29.

_, - (2003): «International Aid and National Entrepreneurship: A Comparative Analysis of Pro-American Business Networks in Southern Europe, 1950-1975». Business and Economic History On-Line 1 (http://www.thebhc.org/BEH/03/puig-alvaro.pdf).

Puig, N. y Fernández, P. (2001): «Modernising Spanish Companies: The Implementation of Modern Management Ideas in Spain, 1945-1975», comunicación presentada a EGOS $17^{\text {th }}$ Colloquium, Lyon, 5-7 julio.

- (2003): «The Education of Spanish Entrepreneurs and Managers: Madrid and Barcelona Business Schools». Historica Paedagogica 39 (5), pp. 651-672.

SAnford, W. (1987): The American Business Community and the European Recovery Plan 1947-1952. NuevaYork: Garland.

SAN RomÁn, E. (1999): Ejército e industria. El nacimiento del INI. Barcelona: Crítica.

SÁnchez, G. y TAscón, J. (eds.), (2003): Los empresarios de Franco. Política y economía en España, 1936-1957. Barcelona: Crítica.

SEgRETo, L. (2001): «Europe vs. United States or bellum omnium contra omnes? COCOM, National Economic Interests, Pressure Groups and Politics in East-West Trade in the 1950's and 1960's», comunicación presentada a $5^{\text {th }}$ European Business History Association Annual Congress, Oslo, 31 agosto - 1 septiembre.

SIERRA F. (1953): La concentración económica de las industrias básicas españolas. Madrid: Instituto de Estudios Políticos.

STANFORD RESEARCh InSTITUTE (1972): Las inversiones norteamericanas en España. Barcelona: Cámara de Comercio Americana en España.

TAscóN, J. (2002): «Inversiones y empresas norteamericanas en España, 1929-1964», comunicación presentada al Seminario La americanización en España: 50 años de influencia económica y social, Universidad Complutense de Madrid, 12-13 septiembre.

- (2003): «Capital internacional antes de la «internacionalización del capital» en España, 1936-1959», en G. Sánchez y J. Tascón (eds.), Los empresarios de Franco. Política y economía en España, 1936-1957. Barcelona: Crítica, pp. 281-306.

TorRes, E. (dir.), (2000): Los cien empresarios españoles del siglo XX. Madrid: LID Editorial Empresarial.

US Department of Commerce (1975): Historical Statistics of the United States. Colonial Times to 1970. Washington D.C.: US Bureau of the Census. 
VALDAlisco, J. M. (2002): «Grupos empresariales y desarrollo económico en España en el siglo XX». Revista de Historia Económica XX (3), pp. 577-624.

Viñas, A., Viñuela, J., Eguidazu, F., Fernández, C. y Florensa, S. (1979): Política comercial exterior de España (1931-1975). Madrid: Banco Exterior de España.

VIÑAs, A. (1981a): Los pactos secretos de Franco con Estados Unidos. Bases, ayuda económica, recortes de soberanía. Barcelona: Grijalbo.

- (1981b): «La primera ayuda económica norteamericana a España», en Ministerio de Comercio, Lecturas de economía española e internacional, Homenaje al 50 aniversario del cuerpo de Técnicos Comerciales del Estado. Madrid: Ministerio de Comercio, pp. 49-90.

- (1984): Guerra, dinero y dictadura. Ayuda fascista y autarquía en la España de Franco. Madrid: Crítica.

- (2003): En las garras del águila. Los pactos con Estados Unidos, de Francisco Franco a Felipe González (1945-1995. Barcelona: Crítica.

WiLKINS, M. (1974): The Maturing of Multinational Enterprise: American Business Abroad from 1914 to 1970. Cambridge, MA: Harvard University Press.

Zeitlin, J. y Herrigel, G. (eds.), (2000): Americanization and Its Limits. Reworking US Technology and Management in Post-War Europe and Japan. Oxford: Oxford University Press.

Zunz, O. (1998): Why the American Century. Chicago: University of Chicago Press. 